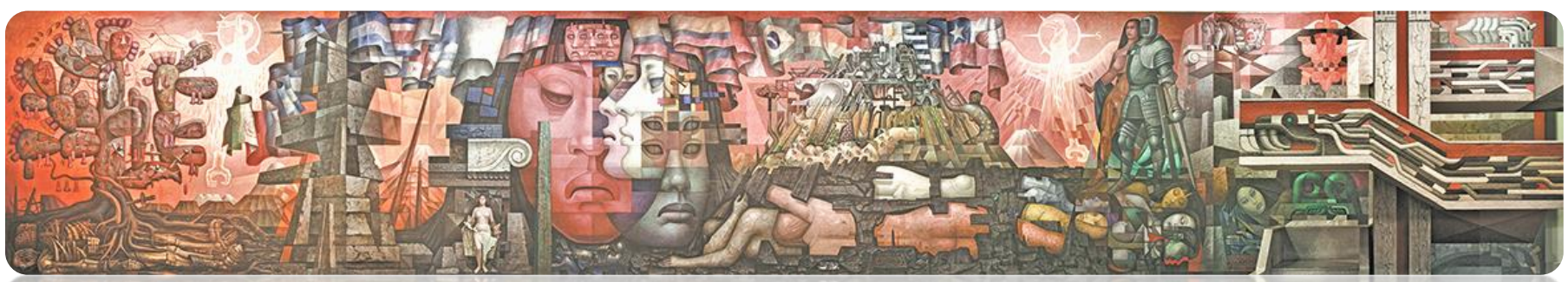

Rev. Hist., $N^{\circ} 28$, vol. 2, Julio-Diciembre 2021: 138-168

ISSN 0717-8832

https://doi.org/10.29393/RH28-30MCJF50030

\title{
Los mapuche de Concepción y la frontera inca: revisión de fuentes tempranas y nuevos datos*
}

\author{
The Mapuche of Concepción and the Inca Frontier: Review of Early Sources and New \\ Data
}

\author{
José Manuel Zavala** \\ Tom D. Dillehay ${ }^{* * *}$ \\ Daniel M. Stewart**** \\ Gertrudis Payàs***** \\ Francisco Javier Medianero******
}

\footnotetext{
* Esta investigación se realizó en el marco del Proyecto FondeCYT Regular N 1170551 (2017-2020), "Tras la ruta del oro. Los habitantes de La Araucanía frente a la ocupación española del siglo XVI, recepción, adaptación y resistencia", financiado por la Agencia Nacional de Investigación Científica y Desarrollo (ANID) del Gobierno de Chile. Nuestros más sentidos agradecimientos a las lingüistas Belén Villena y Lydia Fossa por sus orientaciones respecto de la toponimia y la antroponimia en mapudungun y en quechua respectivamente. Agradecemos igualmente las valiosas sugerencias de los evaluadores de este artículo.

** Universidad de Chile, Facultad de Filosofía y Humanidades; Departamento de Ciencias Históricas, Chile, Santiago. https://orcid.org/0000-0001-6852-1222. Correo electrónico: josezavala@uchile.cl

*** Universidad Austral de Chile, Escuela de Arqueología, Chile, Valdivia. ORCID: https://orcid.org/0000-0002-87102805. Correo electrónico: tom.d.dillehay@vanderbilt.edu

**** Pontificia Universidad Católica de Valparaíso, Chile, Valparaíso.ORCID: https://orcid.org/0000-0003-2466-7320. Correo electrónico: danielmoroni@hotmail.com

***** Universidad Católica de Temuco, Chile, Temuco; Universidad de Almería, Almería, España. ORCID: https://orcid.org/0000-0002-9117-8108.Correo electrónico: gpayas@uct.cl

****** Universidad Católica de Temuco, Chile, Temuco. ORCID: https://orcid.org/0000-0002-7860-2533.Correo electrónico: javiermedianero@gmail.com
} 


\section{RESUMEN}

A partir de la revisión de fuentes coloniales escritas e iconográficas, de estudios arqueológicos y de la toponimia, se analiza la validez de la hipótesis de la presencia inca hasta el río Biobío. Para ello, se presentan una serie de evidencias de diverso origen, que permiten entender mejor la compleja realidad sociocultural de los habitantes de lo que los españoles denominaron "Provincia de Concepción" o Penco, cuando se establecieron allí a mediados del siglo XVI impulsados por la búsqueda de oro y mano de obra indígena. En ese sentido, la temprana explotación hispana de lavaderos de oro en la zona, particularmente en Quilacoya, inducen a buscar los antecedentes prehispánicos de esta minería que, de haber existido, solo puede entenderse en el marco de la expansión del Tawantinsuyu.

Palabras clave: economía aurífera, lavaderos de oro, fronteras incas, mapuche siglo XVI, Tawantinsuyu, Quilacoya

\section{ABSTRACT}

Based on the review of written and iconographic colonial sources, archaeological studies, and toponymy, in this article we analyze the validity of the hypothesis of the Inca presence down to the Biobío River. To achieve this, we present a series of databases of diverse origin that allow us to better understand the complex sociocultural reality of the indigenous peoples of what the Spanish called the "province of Concepción" or Penco. The Spanish settled this region in the mid-sixteenth century in search of gold and indigenous labor. In this sense, the early Hispanic exploitation of gold placers in the area, particularly in Quilacoya, leads us to investigate the antecedents of gold mining in the region, and whether it might have existed in late pre-Hispanic times, within the framework of the expansion of Tawantinsuyu.

Keywords: Gold economy, Gold placers, Inca frontiers, Mapuche 16th century, Tawantinsuyu, Quilacoya.

Recibido: julio 2021

Aceptado: octubre 2021 


\section{Introducción}

En el marco de una investigación en curso sobre la economía aurífera en la Araucanía durante el siglo XVI ${ }^{1}$, la búsqueda del origen de los lavaderos de oro de Quilacoya nos ha llevado a la relectura de las fuentes tempranas que tratan sobre el avance y la instalación de los conquistadores peninsulares, en el área comprendida entre los ríos Itata y Biobío. Territorio que, a contar de 1550, formó parte de la jurisdicción de Concepción, una vez fundada dicha ciudad por los españoles en el valle de Penco. Estos testimonios nos permiten volver sobre la cuestión del contacto inca/mapuche y de la frontera suroccidental del Tawantinsuyu, materia clave para determinar si los lavaderos de oro de Quilacoya ya habían sido explotados o, a lo menos ensayados, antes de la llegada de los españoles.

En relación con la interrogante planteada sobre una eventual minería prehispánica en la región, este trabajo se propone mostrar la complejidad sociocultural, militar y económica existente en el área al momento del arribo de los españoles. Nuestra hipótesis es que dicha complejidad refleja si no una presencia efectiva, a lo menos la tentativa de los incas por instalarse en la zona, particularmente en las áreas de yacimientos auríferos, especialmente en Quilacoya. Por otra parte, esta complejidad sociocultural se entiende mejor en el marco de una relación de larga duración de las sociedades del sur del río Itata con aquellas ligadas al mundo andino; relación indirecta en un primer momento pre-inca o inca inicial y, directa, en un momento inca posterior durante el cual los cuzqueños habrían alcanzado su máxima expansión meridional ${ }^{2}$.

El gran desarrollo socioeconómico del área de Concepción previo a la presencia española se evidencia claramente en los primeros testimonios hispanos y, sin embargo, esta cuestión no ha sido lo suficientemente destacada por la historiografía chilena. Efectivamente, una lectura detallada de las fuentes permite documentar una economía agro-pastoril floreciente para el área, basada en productos característicos del mundo andino pero que no requerían irrigación artificial dadas las características climatológicas de la región. Por otra parte, la organización militar altamente especializada que describen los primeros testimonios no se puede entender fuera del marco de una experiencia bélica contra un enemigo extranjero poderoso como lo fueron los incas.

\footnotetext{
${ }^{1}$ Zavala, José Manuel; Dillehay, Tom; Medianero, Francisco Javier; y Payàs, Gertrudis. 2016. Tras la ruta del oro. Los habitantes de La Araucanía frente a la ocupación española del siglo XVI, recepción, adaptación y resistencia (Manuscrito Propuesta de Fondecyt Regular 2017-2020), Santiago, Archivo CONICYT/ ANID.

2 En un trabajo reciente sobre el pron o quipu mapuche, planteamos como hipótesis la idea de que en las versiones documentadas de este artefacto se puede apreciar, primero, un influjo andino pre-inca y, posteriormente, otro propiamente inca. Zavala, José Manuel; Bachraty, Dagmar y Payàs, Gertrudis. 2021. "El pron o quipu mapuche según fuentes coloniales y datos arqueológicos: antecedentes sobre su origen, uso y función", en Boletín del Museo Chileno de Arte Precolombino, Vol. 26, №1, Santiago, pp. 41 - 55.
} 
El abordaje metodológico de este trabajo es interdisciplinario y se plantea desde una perspectiva etnohistórica. Las evidencias principales que aportamos provienen de fuentes históricas, alguna inéditas, y se combinan, cuando es posible, con datos e interpretaciones arqueológicas y lingüísticas, principalmente toponímicas en este último caso. Somos conscientes de las limitaciones y sesgos de las fuentes escritas, por lo mismo realizamos una lectura crítica de ellas y tratamos de contrastarlas con informaciones y análisis provenientes de las otras disciplinas, lo que no es siempre posible. Cualquiera que se interese por los temas relativos a las sociedades indígenas del siglo XVI reconoce las limitaciones metodológicas que esta tarea implica y las pocas certezas que lamentablemente se pueden establecer, por lo que sin duda lo que planteamos en este trabajo es una propuesta que debe ser sometida a verificación por trabajos ulteriores.

Con todo, no cabe duda que una relectura de los testimonios hispanos tempranos, en particular de los de la primera generación de conquistadores, muestra, más allá de las exageraciones o imprecisiones que sin duda contienen, elementos descriptivos reales, puesto que del diagnóstico que hicieran de la realidad dependían sus vidas y el futuro de la empresa conquistadora. Los informes militares y administrativos posteriores, como el de Miguel de Olavarría, también contienen esa intención de dar cuenta de una realidad para mejor dominarla, con lo cual muchos de los datos que proporcionan se dan desde lo que sus autores consideran creíble. Por supuesto que cuando estos testimonios se refieren a situaciones anteriores a la presencia hispana lo hacen sobre versiones no presenciales y orales, no podría ser de otro modo, pero por lo menos en el caso de Olavarría hay un ejercicio de complementación de las versiones recogidas de informantes indígenas con sus propias observaciones en terreno.

\section{Sobre la frontera suroccidental del Tawantinsuyu}

La cuestión sobre hasta dónde llegaron los incas hacia el sur, por el lado occidental de Los Andes, es un tema que ha estado presente en el debate histórico-antropológico chileno desde temprano ${ }^{3}$, y que ha tenido un nuevo impulso con el desarrollo de investigaciones arqueológicas a partir de la década de 1980.

\footnotetext{
3 Por ejemplo: Medina, José Toribio. 1882. Los aborijenes de Chile, Santiago, Gutenberg; Latcham, Ricardo. 1908. “¿Hasta dónde alcanzó el dominio efectivo de los Incas en Chile?", en Revista Chilena de Historia Natural, N 12, 4, Santiago, pp. 178 - 199; Latcham, Ricardo. 1924. "La organización social y creencias religiosas de los antiguos araucanos", Publicaciones del Museo de Etnología y Antropología Tomo III, Santiago, Imprenta Cervantes, pp. 245 868; Guevara, Tomás. 1908. Psicolojia del pueblo araucano, Santiago, Imprenta Cervantes; Guevara, Tomás. 1925. Chile prehispano. Santiago, Universidad de Chile; Uhle, Max. 1911. La esfera de influencia del país de los Incas, IV Congreso científico ( $1^{\circ}$ pan-americano) del 25 de diciembre de 1908 al 5 de enero de 1909, Tomo II, Santiago, pp. 260 - 281; Uhle, Max. 1912. "Arqueología Sudamericana”, en Revista Chilena de Historia y Geografía, N IV, 8, Santiago, pp. 411 - 425; Gusinde, Martín. 1916. "Medicina e higiene de los antiguos araucanos", Congreso Católico Araucanista de Santiago, Santiago, Publicaciones del Museo de Etnología y Antropología, pp. 87 - 121.
} 
En efecto, desde que Dillehay y Gordon ${ }^{4}$ publicaron su trabajo sobre los diversos tipos de frontera que podían distinguirse en el extremo suroccidental del Tawantinsuyu, dos grandes conjuntos de investigaciones han estado buscando pistas sobre el avance inca hacia el sur. Por una parte, las investigaciones arqueológicas y las síntesis etnohistórico-arqueológicas sobre Chile Central ${ }^{5}$. Por otra parte, encontramos los trabajos sobre la Araucanía y su prolongación meridional que se han centrado en análisis cerámicos y otras tecnologías ${ }^{6}$ o en estudios de corte

${ }^{4}$ Dillehay, Tom y Gordon, Américo. 1988. “La actividad prehispánica de los incas y su influencia en La Araucanía”, en Dillehay, Tom y Netherly, Patricia, La Frontera del Estado Inca, Quito, Fundación Alexander Von Humboldt y Editorial Abya Yala, pp. 183 - 197.

${ }^{5}$ Entre otros autores: Andrade, Pedro; Silva, Francisco; Mengozzi, Francesca; Urzúa, Paula; Campbell, Roberto y Hernández, Javier. 2012. "Influencias incaicas más allá del Cachapoal: el caso del sitio Palquibudi, cuenca media del río Mataquito", Actas del XVIII Congreso Nacional de Arqueología Chilena. Congreso organizado por la Sociedad Chilena de Arqueología, Santiago; Berenguer, José. 2013, "Unkus ajedrezados en el arte rupestre del sur del Tawantinsuyu: ¿La estrecha camiseta de la nueva servidumbre?", en Las tierras altas del Área Centro Sur Andina entre el 1000 y el 1600 d.C. TANOA II. Taller Internacional de Arqueología del Noroeste Argentino y Andes Centro Sur. M.E. Albeck., M. Ruiz y B. Cremonte (eds.). Juju: EdiUNJu., pp. 311-352; Cornejo, Luis. 2014. "Sobre la cronología del inicio de la imposición cuzqueña en Chile" en Estudios Atacameños, № 47, San Pedro de Atacama, pp. 101 - 116; Cornejo, Luis. 2018. "El centro político inka en el extremo austral del Tawantinsuyu (Chile Central)", Boletín del Museo Chileno de Arte Precolombino, N²3, vol.1, Santiago, pp.133 - 158; León, Leonardo. 1983. “Expansión inca y resistencia indígena en Chile, 1470-1536", en Chungara, №10, Arica, pp. 95 - 115; Planella, María Teresa; Stehberg, Rubén; Niemeyer, Hans; Tagle, Blanca y del Río, Carmen. 1993. La fortaleza indígena del Cerro Grande de La Compañía (valle del Cachapoal) y su relación con el proceso expansivo meridional incaico, Actas del XII Congreso Nacional de Arqueología Chilena) / Boletín del Museo Regional de la Araucanía, Tomo II, Temuco, Ediciones de la Dirección de Bibliotecas, Archivos y Museos, pp. 403 - 421; Sánchez, Rodrigo. 2004. "El Tawantinsuyu en Aconcagua (Chile central)", en Chungara, $N^{\circ} 36$, 2, Arica, pp. 325 - 336; Silva, Osvaldo. 1983. ¿Detuvo la batalla del Maule la expansión inca hacia el sur de Chile? en Cuadernos de Historia, N 3, pp. 7 - 25; Silva, Osvaldo. 1986. "Los promaucaes y la frontera meridional incaica en Chile", Cuadernos de Historia, Nº 6, Santiago, pp. 7 - 16; Sotomayor, Gonzalo, Stehberg, Rubén y Cerda, Juan Carlos. 2016. "Mapocho incaico norte", Museo Nacional de Historia Natural, Chile, № 65, Santiago, pp. 109 - 135; Stehberg, Rubén. 1976. "La Fortaleza de Chena y su Relación con la Ocupación Incaica de Chile Central", Boletín del Museo Nacional de Historia Natural de Chile, N²3, Santiago; Stehberg, Rubén. 2013. "Caminos, guacas y el reducto fortificado de cerro el peral: instalaciones para el control inca del paso de Chada, Chile Central", Boletín del Museo Nacional de Historia Natural, № 62, Santiago, pp. 129 - 146; Stehberg, Rubén. 2016. "Plataforma ceremonial Ushnu inca de Chena, Valle del Maipo, Chile", en Chungara, Vol. 48, № 4, Arica, pp. 557 588; Stehberg, R., M. Planella y H. Niemeyer. 1997. "Complejidad arquitectónica de las ruinas prehispánicas de Chada en la antigua ruta entre los ríos Maipo y Cachapoal", Xama № 6, vol.11, Mendoza, pp. 53 - 64; Stehberg, Rubén y Rodríguez, Antonio. 1989. "Ofertorio mapuche-incaico en el cerro Tren de Doñihue”, Revista Museos, N 6, pp. 8 11; Stehberg, Rubén y Sotomayor, Gonzalo. 2012. "El Mapocho Incaico", Boletín del Museo Nacional de Historia Natural, N 61, Santiago, pp. 85 - 149; Rivera, Mario A., y Hyslop, John. 1984. "Algunas estrategias para el estudio del camino del inca en la región de Santiago, Chile", Cuadernos de Historia, № 4, Santiago, pp. 109 - 128; Téllez, Eduardo. 1990. "De incas, picones y promaucaes", Cuadernos de Historia, N 10, Santiago, pp. 69 - 86; Uribe, Mauricio y Sánchez, Rodrigo. 2016. "Los incas en Chile. Aportes de la arqueología chilena a la historia del Tawantinsuyo (ca. 1400 a 1536 años d.C.)", en Falabella, Fernando; Uribe, Mauricio; Sanhueza, Lorena; Aldunate, Carlos e Hidalgo, Jorge. Prehistoria en Chile desde sus primeros habitantes hasta los Incas, Santiago, Editorial Universitaria, pp. 529 572.

${ }^{6}$ Adán Leonor, Mera, Rodrigo; Navarro, Ximena; Campbell, Roberto; Quiroz, Daniel y Marco Sánchez. 2016. “Historia prehispánica en la región Centro-Sur de Chile: Cazadores-recolectores holocénicos y comunidades alfareras (ca. 10.000 a.C. a 1.550 años d.C.)", en Falabella, Fernanda y otros (Eds.) Prehistoria en Chile. Desde sus primeros habitantes hasta los Incas, Santiago, Editorial Universitaria; Bahamondes, Francisco. 2007. "Las sociedades 
interdisciplinar que combinan evidencias arqueológicas con datos linguísticos, etnohistóricos y etnográficos ${ }^{7}$.

Desafortunadamente, se han realizado pocas investigaciones arqueológicas entre los ríos Itata y Biobío. Generalmente se ha identificado este espacio como haciendo parte de una frontera socioeconómica del imperio inca donde este no llegó a ejercer un control políticomilitar efectivo, pero sí alcanzó a influir cultural y económicamente, algo propio de su estrategia expansiva informal ${ }^{8}$. Con menos precisión, también se ha definido este territorio como una zona de interdigitación cultural entre sociedades de raigambre andina más septentrionales y otras de tradición local ${ }^{9}$.

Resumiendo, de manera muy general, lo avanzado hasta ahora por las investigaciones sobre la expansión inca hacia el sur, es posible afirmar que:

a. Está demostrado que los incas ejercieron, en algún momento, un control político, militar y económico hasta la cuenca del río Cachapoal ${ }^{10}$.

prehispánicas tardías y coloniales de La Araucanía: la cerámica bícroma como elemento de continuidad socio-cultural (S.X-XVIII D.C.)", VI Congreso Chileno de Antropología, Tomo 2 (1919-1931). Congreso organizado por el Colegio de Antropólogos de Chile, Santiago; Bahamondes, Francisco. 2009. La cerámica prehispánica tardía de Araucanía septentrional: el complejo arqueológico El Vergel y su relación con la hipótesis del proceso de andinización. Universidad de Chile, Memoria para optar al título profesional de Arqueólogo; Bahamondes, Francisco. 2010. "Las poblaciones tardías de Araucanía Septentrional: el complejo El Vergel y su relación con el proceso de andinización", Actas del XVII Congreso Nacional de Arqueología Chilena. Congreso organizado por la Sociedad Chilena de Arqueología, pp. 551 - 461; Campbell, Roberto. 2004. El trabajo de los metales en la Araucanía (siglos X a XVII d.C.), Universidad de Chile, Memoria para optar al título de Arqueólogo. Dillehay, Tom. 2011. Monumentos, imperios y resistencia en Los Andes: el sistema de gobierno mapuche y las narrativas rituales, Antofagasta, Imprenta Qillqa y Universidad Católica del Norte.

7 Dillehay. 2011, Monumentos; Dillehay, Tom. 2020. Montículos "vivientes", imperios y resistencias en los Andes. Narrativas rituales del esapcio y gobierno mapuche, Antofagasta, Imprenta Qillqa y Universidad Católica del Norte; Moulian, Rodrigo y Catrileo, María. 2013. "Kamaska, kamarikun y müchulla: préstamos lingüísticos y encrucijadas de sentido en el espacio centro y sur andino”, en Alpha, N³7, Osorno, pp. 249 - 263; Inostroza, Iván. 2013. “La colonización minera y agrícola en la ciudad Imperial del Sur de Chile: 1551-1561", en Revista Complutense de Historia Americana, Vol. 39, Madrid, pp. 107-127; Moulian, Rodrigo y Espinoza, Pablo. 2015. "Impronta andina entre los Kamaskos del Wenuleufu", en Atenea, N512, Concepción pp. 311 - 230; Moulian, Rodrigo; Latorre, Elvira; Caniguan, Jaqueline y Bahamondes, Francisco. 2020. "Pañilwe ñi dungu: las voces del metal”, en Revista Antropologías del Sur, $N^{\circ} 7,13$, Santiago, pp. 1 - 25; Zavala, José Manuel y Dillehay, Tom. 2010. “El 'Estado de Arauco' frente a la conquista española: estructuración sociopolítica y ritual de los araucano-mapuches en los valles nahuelbutanos durante los siglos XVI y XVII", en Chungara, N 42, vol.2, Arica, pp. 433 - 450.

8 Dillehay y Gordon. 1988, "La Actividad", p. 194.

${ }^{9}$ Bahamondes. 2010, Las poblaciones, pp. 459 - 460; Bahamondes et al. 2006. Bahamondes, Francisco, Silva, Carmen y Campbell, Roberto. 2006. "La Candelaria: un yacimiento funerario del complejo El Vergel en el curso inferior del río Bío-Bío", en Boletín de la Sociedad Chilena de Arqueología, №39, Santiago, pp. 80 - 81.

${ }^{10}$ Stehberg, Rubén. 1991. "El límite inferior cronológico de la expansión incaica en Chile”, en Xama, N 4, 5, pp. 63 89; Planella, María Teresa y Stehberg, Rubén. 1994. "Etnohistoria y arqueología en el estudio de la fortaleza indígena de cerro grande de la Compañía”, en Chungara, № 26, Arica, pp. 65 - 78; Santillán, Hernando de. 1968 [1563]. Relacion del origen, descendencia, politica y gobierno de los Incas. Biblioteca Peruana, Primera Serie, Tomo III, Lima, Editores Asociados, ETA; Sepúlveda, Jairo; San Francisco, Alex; Jiménez, Bruno y Pérez, Sebastián. 2014. El pucará del cerro La Muralla: Mapuches, Incas y españoles en el Valle del Cachapoal, Santiago, Mutante editores; Stehberg, 
b. Existen evidencias arqueológicas confirmadas de presencia inca haste el río Mataquito ${ }^{11} \mathrm{y}$ otras referencias no confirmadas que amplian la ocupación incásica hasta el río Maule ${ }^{12}$. Por otra parte, las fuentes peruanas señalan que estos alcanzaron el río Maule ${ }^{13}$.

c. Fuentes etnohistóricas chilenas, no tan tempranas pero muy fiables, señalan que los incas habrían llegado hasta el río Biobío ${ }^{14}$.

d. Una serie de datos arqueológicos, lingüísticos y etnográficos evidencian un influjo cultural andino significativo, inca o pre-inca, presente desde el río Biobío al sur ${ }^{15}$.

e. Por último, algunos autores han planteado que los rasgos culturales incas presentes en la Araucanía podrían deberse a la presencia de yanaconas traidos del norte en el marco de la ocupación española de la segunda mitad del siglo XVI ${ }^{16}$.

En síntesis, hasta la fecha, las investigaciones arqueológicas en el area de estudio de este trabajo confirman la presencia inca hasta el río Mataquito y el influjo andino en toda el área Centro-Sur, mientras que las fuentes etnohistóricas permiten prolongar, sin reparos, la expansión cusqueña hasta el río Maule y, menos consensuadamente, hasta el río Biobío. Es en relación a esta última alternativa, la más meridional, que este artículo presenta algunas nuevos antecedentes e interpretaciones, basadas mayormente en datos de las fuentes etnohistóricas. Dicho lo anterior, tampoco se puede descartar que rasgos culturales identificados con el universo inca sean de origen colonial, lo que no invalida necesariamente la existencia previa de

\footnotetext{
Rubén y Rodríguez, Antonio. 1995. "Ofrendas mapuche-incaicas en el cerro Tren-Tren de Doñihue, valle de Cachapoal”, en Revista Tawantinsuyu N 1, Canberra, pp. 29 - 35; Vivar, Jerónimo de. 1966 [1558]. Crónica y relación copiosa y verdadera de los reynos de Chile hecha por Gerónimo de Bibar, Santiago, Fondo histórico y bibliográfico José Toribio Medina, Biblioteca Nacional de Chile.

11 Andrade et al. 2012, "Influencias".

12 León Echaíz, René. 1957. Prehistoria de Chile central, Talca, Poblete; Keller, Carlos. 1960. Los orígenes de Quillota, Santiago, Editorial Universidad Católica.

${ }^{13}$ Betanzos, Juan de. 2015 [1551-1558]. "Suma y Narración de los Incas" en Hernández Astete, Francisco y CerrónPalomino, Rodolfo (eds.). Juan de Betanzos y el Tahuantinsuyo, Lima, Pontificia Universidad Católica del Perú; Vega, Garcilaso de la. 1609. Comentarios Reales, Lisboa, Oficina de Pedro Crasbeeck.

${ }^{14}$ Olavarría, Miguel de. 1852 [1594]. "Informe de Don Miguel de Olavarría sobre el Reyno de Chile, sus indios y sus guerras", en Gay, Claudio (comp.). Historia Física y Política de Chile: Documentos sobre la Historia, la Estadística y la Geografía de Chile, Tomo Segundo, París, Casa del Autor, pp. 13-54; Rosales, Diego. de. 1877 [1674]. "Historia General de el Reyno de Chile, Flandes Indiano", editado por Vicuña Mackenna, Benjamín, Valparaíso, Imprenta del Mercurio.

${ }^{15}$ Bahamondes. 2007, "Las sociedades"; Bahamondes. 2009, La cerámica; Bahamondes. 2010, "Las poblaciones"; Bahamondes et al. 2006, "La Candelaria"; Campbell. 2004, "El trabajo"; Dillehay, Tom. 1990. "El Formativo del Extremo Sur de Chile", en Gaceta Arqueológica Andina, N 17, Lima, pp. 101 - 114. Dillehay. 2011, Monumentos; Dillehay, Tom. 2020, Montículos; Dillehay y Gordon. 1988, "La Actividad"; Moulian y Catrileo. 2013, "Kamaska"; Moulian y Espinoza. 2015, "Impronta"; Moulian et al. 2020, "Pañilwe"; Payàs, Gertrudis y Villena, Belén. 2021. "Indagaciones en torno al significado del oro en la cultura mapuche. Una exploración de fuentes", en Estudios Atacameños (en prensa), San Pedro de Atacama; Zavala y Dillehay. 2010, "El 'Estado de Arauco'”.

16 Silva, 1986, "Los promaucaes"; Adán et al., 2016, "Historia prehispánica”.
} 
otros de origen prehispánico. En particular, la difusión de ciertos relatos míticos como la venida de Atahualpa pueden haberse generado en el contexto colonial ${ }^{17}$.

\section{La Provincia de Concepción y sus Habitantes, revisitando las fuentes etnohistóricas}

En el vocabulario colonial, la denominada provincia de Concepción o Penco ocupa, grosso modo, el territorio interfluvial delimitado por los ríos Itata y Biobío. Estos dos grandes cauces otorgan un grado de aislamiento a su interfluvio en relación con los territorios de más al norte y de más al sur, lo que confiere a este espacio una cierta unidad geográfica y humana.

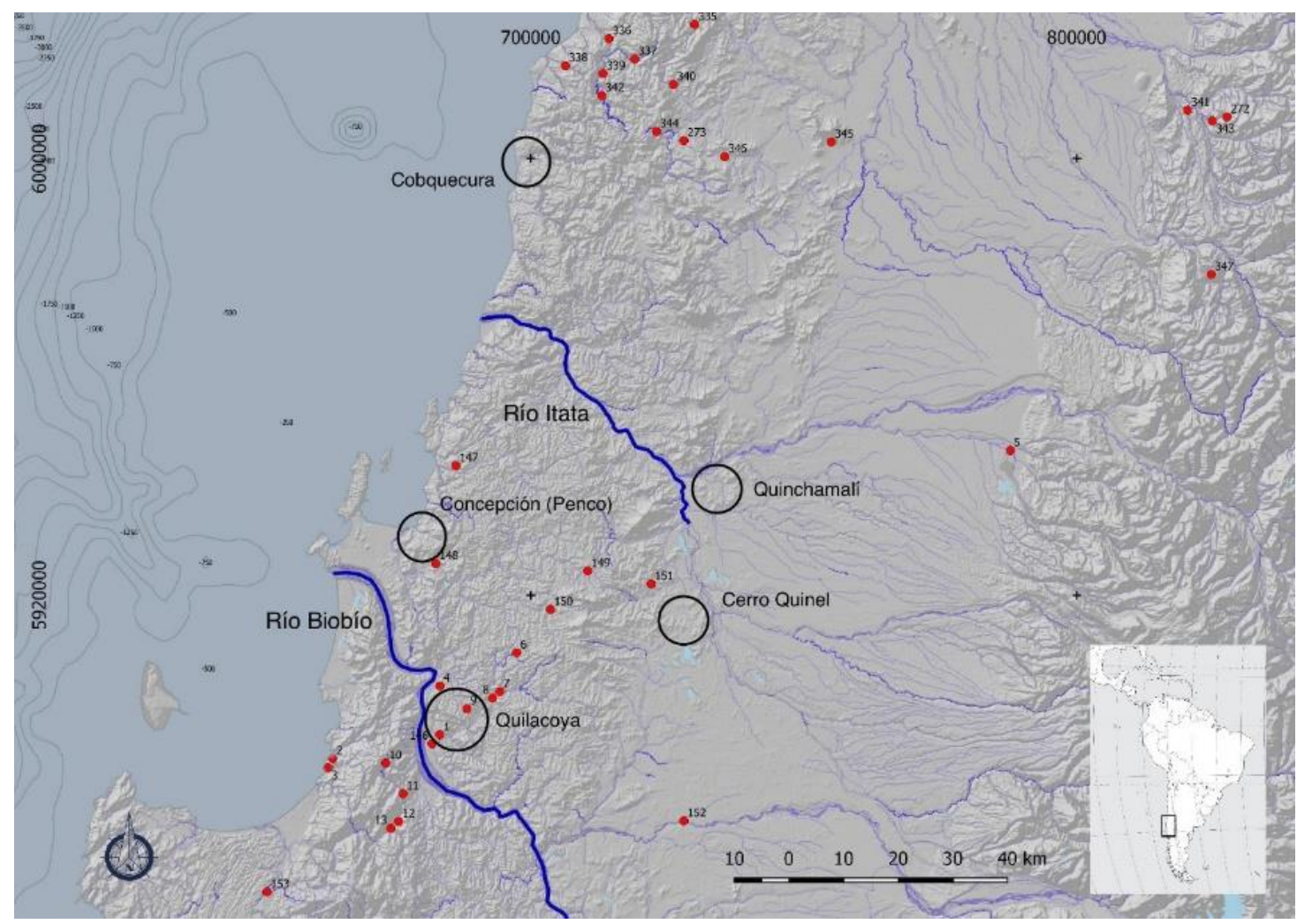

Figura. 1. La "provincia de Concepción" con lugares mencionados en este trabajo y placeres auríferos (en rojo) según registro de SERNAGEOMIN sin asignación cronológica (elaboración F. J. Medianero y J. M. Zavala).

El río Itata aparece en las fuentes tempranas como el punto de extensión más austral de la provincia de los promaucaes, quienes habitaban principalmente entre las cuencas de los ríos Cachapoal y Maule ${ }^{18}$. Este último río constituyó, desde la fundación de Santiago en 1541 hasta

\footnotetext{
${ }^{17}$ Sobre el tema, es interesante el análisis que hace Ajens quien propone una intermediación misional en la difusión del relato del inca rey en el sur chileno. Vd. Ajens, Andrés. 2017 "Conexiones huilliche-altoperuanas en el ciclo de Atahualpa", en Meridional, № 8, 2017, Santiago, pp.153 - 188.

18 Vivar. 1966 [1558], Crónica, p. 138.
} 
la erección de Concepción en 1550, el límite sur de la jurisdicción santiaguina ${ }^{19}$. Desde el principio, el río Biobío fue reconocido por los hispanos como el gran obstáculo que separaba a los habitantes del interfluvio Itata/Biobío de los de Arauco $^{20}$.

En este territorio hubo un acercamiento progresivo de los nuevos conquistadores, que partió con la expedición de Almagro en 1535-1536, la que llegó hasta unos 500 km al norte del río Itata: al valle de "Chile" - Aconcagua-; aunque, según Góngora Marmolejo ${ }^{21}$, una avanzada a cargo de Gómez de Alvarado habría llegado a la provincia penquista en búsqueda de oro. Posteriormente, hubo acercamientos más permanentes, tras la fundación de la ciudad de Santiago (1541) a unos $440 \mathrm{~km}$ al norte del Itata y el consecuente repartimiento entre los encomenderos santiaguinos de la mayor parte de los habitantes de Chile central, entre los ríos Aconcagua y Maule 22 .

En ese sentido, cabe considerar que la comunicación entre Chile central y la provincia de Concepción debió haber sido fluida mucho antes de la irrupción española de 1550, esto si se considera la facilidad con que la avanzada de Almagro y las exploraciones posteriores de Villagra (1544) y Valdivia (1546) recorrieron el camino entre el Mapocho y los territorios meridionales, cruzando sin grandes dificultades el río Itata. Incluso Villagra dejó en la ribera del Itata en 1544 un destacamento de control para impedir la huida de indígenas hacia el sur $^{23}$.

Claramente los españoles utilizaron una ruta ya existente que luego se convirtió en el "Camino Real" que uniría las ciudades de Santiago y de Concepción. Esta vía - según relata a mediados del siglo XVII Diego de Rosales ${ }^{24}$ - atravesaba el río Ñuble, afluente del Itata, a la altura de Quinchamalí para luego vadear este último río en Quinel y seguir hacia el sur por el valle del mismo nombre - actual comuna de Cabrero-, en busca de la ribera norte del río Claro -actual Yumbel-, para luego torcer en dirección a la costa.

Aunque los indígenas de Santiago y los de Concepción compartían una lengua y muchos otros aspectos, los cronistas del siglo XVI notaron una diferencia fundamental entre ellos: el carácter guerrero y el complejo sistema militar que distinguía a los habitantes de los territorios situados entre los ríos Itata e Imperial ${ }^{25}$. Pero no solo eso, las crónicas tempranas también

\footnotetext{
${ }^{19}$ Valdivia, Pedro de. 1929 [1545-1552]. Cartas de Pedro de Valdivia que tratan del descubrimiento y conquista de Chile. Edición facsimilar dispuesta y anotada por José Toribio Medina, Sevilla, Establecimientos tipográficos de M. Carmona, p. 200.

20 Vivar. 1966 [1558], Crónica, p. 150.

${ }^{21}$ Góngora Marmolejo, Alonso de. 1862 [1575]. Historia de Chile desde su descubrimiento hasta el año de 1575, Santiago, Imprenta del Ferrocarril.

22 Valdivia. 1929 [1545 - 1552], Cartas, p. 42.

23 Ibídem, p. 65.

24 Rosales, Diego de. 2018 [1674]. Historia General de el Reyno de Chile, Flandes Indiano, editado por Vicuña Mackenna, Benjamín, Valparaíso, Imprenta del Mercurio, Forgotten Books, pp. 191 - 197.

25 Vivar. 1966 [1558], Crónica, pp. 153 - 156; Olavarría. 1852 [1594], “Informe”, pp. 19 - 23.
} 
destacan una agricultura y ganadería nada despreciable y una alta densidad demográfica en estos mapuche sureños.

Jerónimo de Vivar ${ }^{26}$ describió con mucho detalle la forma de combatir, las armas y la indumentaria de los combatientes penquistas. Le llamó especialmente la atención un tipo de coraza denominada tanaña, hecha de "pescuezos de ovejas o carneros ${ }^{27 "}$ o de cuero de lobo marino muy resistente, en forma de cono, como "verdugado ${ }^{28 "}$, que solo tenía una obertura para el brazo izquierdo del soldado y que les cubría hasta las rodillas; algunas iban forradas con cuero de corderos pintados y otras recubiertas con tiras de lo mismo en "cruces y aspas" o pintadas.

En la cabeza, los guerreros llevaban una celada de cuero que la cubría casi por completo, salvo por una obertura para el ojo izquierdo; recubrían esta especie de casquete con la piel de cabezas de zorros y pumas $u$ otros felinos, y la parte posterior con plumajes. Estas protecciones e indumentarias las llevaban quienes formaban la primera línea de los escuadrones; pero todos, además de estar "embijados" - se entiende que pintados-, adosaban a sus espaldas pieles de zorros con la cola colgando entre las piernas ${ }^{29}$.

En cuanto a las armas y su uso, Vivar describió variedades que, por sus características y la ubicación entre los combatientes, se deduce que eran aptas para enfrentar conjuntos organizados y blindados de enemigos. El cronista describe picas de madera largas de veinticinco palmos - unos $5 \mathrm{~m}$ aprox. - terminadas con puntas de cobre de "palmo y medio" a "dos palmos" - entre 30 y $40 \mathrm{~cm}$ aprox. - y fijadas con cuerdas de tendones. Estas picas las llevaban los acorazados de la primera línea y, entre estos, se ubicaban otros sin coraza ni celada, armados de astas largas; algunas de estas incluían en un extremo "hachas de pedernal" y otras finalizaban en una maza como una "manzana".

Detrás de esta primera línea, se ubicaba otra hilera de soldados armados con lanzas de quince a dieciséis "palmos" - unos 3 a 3,3 m aprox. - que terminaban en una especie de hachas de cobre con diferentes formas: de "dos o tres picos"; "anchas" o "como martillos". En medio del escuadrón, iban otros con picas, pero "sin capa" - entendemos sin coraza-, estos y los lanceros de la segunda línea llevaban también unos "garrotes" arrojadizos muy dañinos. Finalmente, se encontraba otra hilera de combatientes con "varas largas" que sostenían lazos de fibra vegetal usados para estrangular o derribar a distancia al enemigo. También contaban en los combates con escuadrones de flecheros ${ }^{30}$.

\footnotetext{
${ }^{26}$ Vivar. 1966 [1558], Crónica, pp. 153 - 156.

27 Entendemos que se refiere a que las tanañas estaban fabricadas por adición de vértebras cervicales de auquénidos, constituyendo así una especie de malla protectora.

28 Verdugado: Vestidura que las mujeres usaban debajo de las basquiñas para ahuecarlas (RAE).

29 Vivar. 1966 [1558], Crónica, p. 153 - 155.

30 Ibídem.
} 
El detalle y precisión de la descripción de este cronista respaldan su veracidad, coincidiendo bastante con los relatos de Pedro de Valdivia, quien, en su primer enfrentamiento con los penquistas, en 1550, expresaba la sorpresa y admiración que estos le provocaban:

"Venían en extremo muy desvergonzados, en cuatro escuadrones, de la gente más lucida e bien dispuesta de indios que se ha visto en estas partes, e más bien armada de pescuezos de carneros y ovejas y cueros de lobos marinos, crudíos, de infinitas colores, que era en extremo cosa muy vistosa, y grandes penachos, todos con celadas de aquellos cuero, a manera de bonetes de clérigos, que no hay hacha de armas, por acerada que sea, que haga daño al que las traxere, con mucha flechería y lanzas a veinte e a veinte e cinco palmos , y mazas y garrotes; no pelean con piedras." ${ }^{31}$

Estas descripciones de llamativas indumentarias y armamento encuentran un reflejo gráfico en los dibujos que elaboró el monje Diego de Ocaña para dar cuenta de su viaje a Chile (Figura 2; recuadros $\mathrm{a}, \mathrm{b}$ y c) medio siglo después. Los diseños de Ocaña no surgieron de su observación directa, ya que difícilmente el monje jerónimo pudo haber alcanzado las provincias sureñas de Chile en momentos de la gran rebelión de 1598-1602. Sin embargo, tratan de ser lo más fidedignas a los relatos de testigos locales y antecedentes directos, como bien lo han señalado Eugenio Pereira Salas ${ }^{32}$ y Beatriz Peña ${ }^{33}$.

Evidentemente, no es posible establecer una similitud calcada entre las descripciones de los primeros cronistas y las representaciones gráficas de Ocaña, pero poseen semejanzas respecto al armamento usado, al tipo de corazas, celadas y plumajes que vestían los soldados. Por otra parte, si comparamos los dibujos de Ocaña con el que unos años más tarde trazó Guaman Poma de Ayala (Figura 2; recuadro d) escenificando un enfrentamiento -anterior a la conquista española- entre el ejército inca con los "indios de Chile", nos encontramos con una curiosa y contradictoria analogía: quienes llevan celadas, portan escudos y usan variedad de armas son los soldados incas, en tanto los chilenos destacan por la simplicidad de su equipamiento.

\footnotetext{
${ }^{31}$ Valdivia. 1929 [1545-1552], Cartas, p. 204 (Carta al emperador Carlos V, Concepción, 15 de octubre 1550).

32 Pereira Salas, Eugenio. 1995. "Introducción y notas", en Ocaña, Diego de. Viaje a Chile: Relación del viaje a Chile, año de 1600, contenida en la crónica de viaje intitulada "A través de la América del Sur", Santiago, Editorial Universitaria.

33 Peña, Beatriz. 2011. Imágenes contra el olvido: El Perú colonial en las ilustraciones de fray Diego de Ocaña, Lima, Fondo Editorial de la Pontificia Universidad Católica del Perú; Peña, Beatriz. 2016. Fray Diego de Ocaña: olvido, mentira y memoria, Alicante, Publicaciones de la Universidad de Alicante.
} 
Figura 2. Representaciones de guerreros mapuches en Ocaña y en Guaman Poma de Ayala.
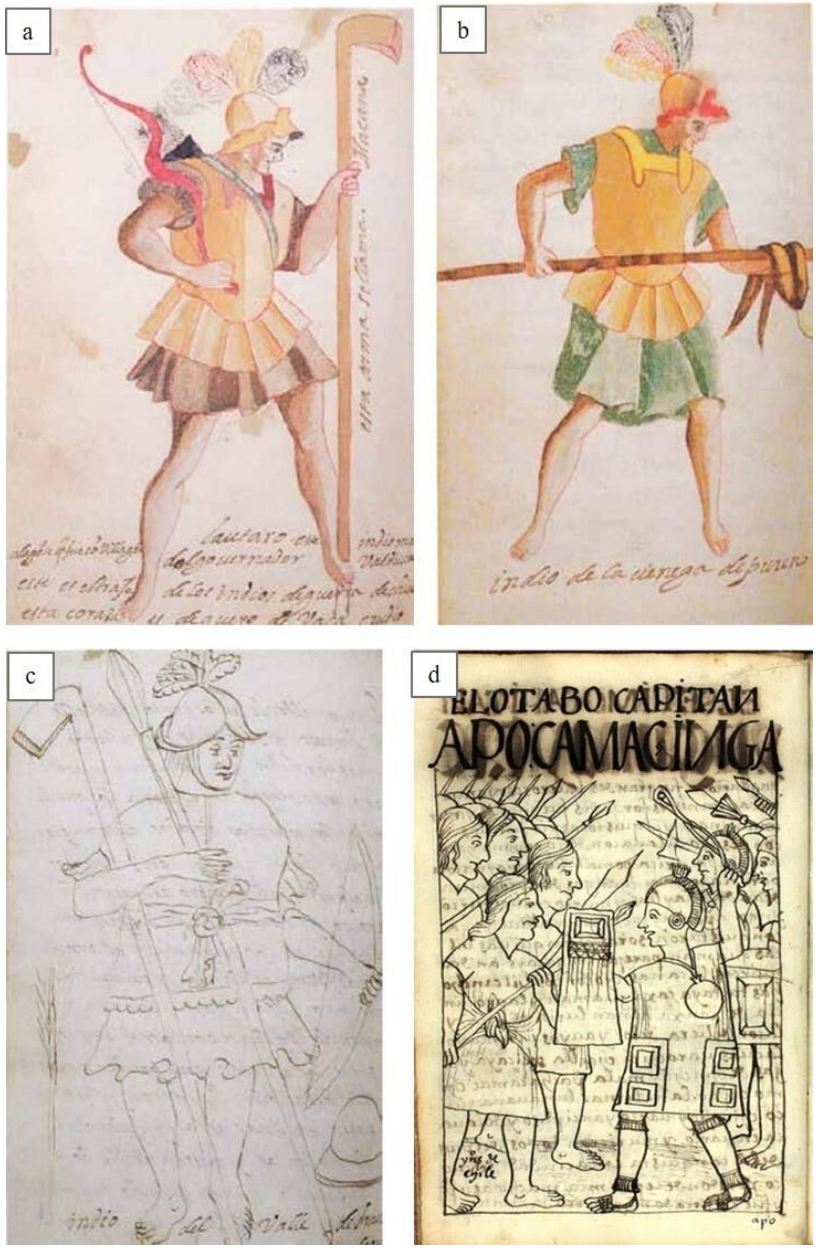

a) "Lautaro: Este indio mató a la gente que fue con Villagrán, del Gobernador Valdivia. Este es el traje de los indios de guerra de chile: esta coraza es de cuero de vaca crudío. Esta arma se llama macana" ${ }^{34}$. b) "Indio del Valle de Arauco. Caupolicán. Este mató al Gobernador Valdivia" ${ }^{35}$. c) "Indio de la ciénega de puren" ${ }^{36}$. d) "EL OTABO CAPITAN / APO CAMAC INGA / yndios de Chile" 37.

\footnotetext{
34 Ocaña, Diego. 1995 [1600 - 1607]. Viaje a Chile: Relación del viaje a Chile, año de 1600, contenida en la crónica de viaje intitulada "A través de la América del Sur". Introducción y notas de Eugenio Pereira Salas, Santiago, Editorial Universitaria, p. 70.

35 lbídem, p. 67.

${ }^{36}$ lbíd., p. 69.

37 Guaman Poma de Ayala, Felipe. 2013 [1615]. El primer nueva crónica y buen gobierno por Felipe Guaman Poma de Ayala. Edición crítica de Murra, John V. y Adorno, Rolena, México, Siglo XXI, p. 136.
} 
En resumen, tanto Vivar como Valdivia y, en general, los cronistas tempranos ${ }^{38}$, se refieren a un tipo de ejército propio de una sociedad con función militar altamente especializada y con un sistema de autoridad bélica jerarquizado que moviliza amplios sectores de una población numerosa. Si adicionamos la presencia de metal en el armamento, específicamente de cobre, este retrato nos describe fuerzas defensivas entrenadas para enfrentamientos con grandes cuerpos de combatientes, como aquellos que aseguraban la expansión inca. Los dibujos de Ocaña refuerzan gráficamente esta idea de complejidad militar y, por su parte, la ilustración de Guaman Poma permite hacer una aproximación, contradictoria y enigmática aún, con el aparataje militar del Tawantinsuyu.

\section{Abundancia de Comidas y Oro}

La complejidad del aparataje militar de los habitantes del sur del río Itata es coherente con las dimensiones económicas y sociales que los testimonios dan cuenta. Al respecto, es muy decidor lo que señala Pedro de Valdivia en sus primeros recorridos por el interfluvio Itata-Biobío. Durante el viaje iniciado en Santiago en 1550 con el propósito de fundar una ciudad en el valle de Penco -el cual, recordemos, ya había reconocido en su exploración de 1546-, el conquistador alcanzó el curso medio de la ribera norte del Biobío - Isla de la Laja-, el 24 de enero de $1550^{39}$. En esa ocasión, Valdivia envía un destacamento a inspeccionar la otra banda del río, el cual encuentra "más de veinte mil indios" y regresan con más de 1.000 cabezas de "ovejas" 40.

Una vez instalado en el pequeño fuerte que era Concepción, Valdivia se dedica a recorrer el territorio y se muestra sorprendido de la abundancia y riquezas que descubre dando cuenta de un territorio poblado por una sociedad sedentaria de guerreros, pastores de llamas y cultivadores de maíz ${ }^{41}$. Vivar, además del maíz, también señala los frijoles y las papas ${ }^{42}$. Podemos observar que estas descripciones dan cuenta de una economía agrícola y pastoril bastante desarrollada, con una base productiva muy similar a la predominante en el espacio andino: cultivo de maíz, frijoles y papas, y crianza de llamas. Los camélidos domésticos, además

\footnotetext{
38 Ercilla, Alonso de. 1574. La Araucana, Salamanca, Casa de Domingo de Portonarijs; Góngora Marmolejo. 1862 [1575], Historia, pp. 20 - 24; Mariño de Lobera, P. 1865 [1595]. Crónica del reino de Chile, Colección de Historiadores de Chile, Tomo 6, Santiago, Imprenta del Ferrocarril, pp. 110 - 122.

39 Valdivia. 1929 [1545-1552], Cartas, p. 201.

${ }^{40}$ Estamos seguros de que las denominadas ovejas o carneros "de la tierra" son llamas y no guanacos. La diferencia la establece claramente Ovalle en la primera mitad del siglo XVII, quien precisa que los guanacos "nunca se domestican" (Ovalle. 1646, Histórica, p. 53). Ya antes, Ocaña las dibuja y señala que las "ovejas" de Chile son las misma que las del Perú (Ocaña. 1995 [1600-1607], Viaje, p. 74). Si subsiste alguna duda, basta preguntarse si es posible pastorear guanacos y obtener de ellos la cantidad de lana suficiente para vestir a la numerosa población que habitaba los valles centrarles y meridionales de Chile.

${ }^{41}$ Valdivia. 1929 [1545 - 1552], Cartas, p. 205. Pedro de Valdivia solo menciona el cultivo del maíz al dar cuenta de las cosechas confiscadas en las islas Santa María y Mocha por Alderete en su expedición marítima desde Concepción a las costas del Arauco en marzo de 1550 (Ibíd., p. 138, Carta a sus Apoderados, Concepción 15 de octubre de 1550). 42 Vivar. 1966 [1558], Crónica, p. 153.
} 
de aportar lana, carne y otras materias primas, servían igualmente para el transporte de carga. El uso de la llama como animal de carga estuvo vigente en Chile Central a lo menos hasta la primera mitad del siglo XVII ${ }^{43}$.

En relación con la búsqueda de oro en Concepción, Valdivia ordena realizar catas para identificar vetas auríferas e informa optimistamente a Carlos $V$, asegurándole que "en ninguna parte se ha dado cata que no saque" ${ }^{\prime 4}$.

A partir de lo expresado por Valdivia, es posible plantear la interrogante respecto a cómo los españoles lograron identificar tan rápidamente la existencia de placeres auríferos en Concepción si bien el más importante lavadero de la provincia, Quilacoya, solo entra en pleno funcionamiento en octubre de 1553 según Mariño de Lovera ${ }^{45}$. Es indudable que cualquier expedición española en territorio americano con pretensiones de conquista debía llevar entre sus filas cateadores de minas -sobre todo de oro- metal que era el que principalmente se buscaba. Los informantes locales fueron fundamentales también en la identificación de las potenciales riquezas presentes en un nuevo territorio, por ello una de las primeras tareas que realizaban los españoles en sus exploraciones era capturar informantes, a lo que ellos denominaban "tomar lengua".

Una segunda cuestión que es posible plantear es si hubo explotación de oro en esta región antes de la conquista hispana. No tenemos información etnohistórica directa para responder a ello. Sin embargo, de lo que estamos seguros es del uso de este metal por los mapuche del sur. En efecto, a la rapidez de la identificación española de yacimientos auríferos podemos sumar informaciones tempranas que señalan la presencia de orfebrería en oro, plata y cobre en los territorios del Itata al sur.

Así lo señaló Vivar, al referirse a las costumbres de la gente de la provincia de Concepción: "Traen brazaletes de oro y de plata y una manera de corona; traen al pescuezo una manera de diadema y de turquesas y de tiritas de oro a manera de estampas. Ellas andan como las de Mapocho, salvo que traen una manera de zarcillos de cobre." ${ }^{46}$

Por su parte, Alonso de Ercilla -contemporáneo de Vivar- también señaló el uso de este tipo de alhajas entre los de Arauco en las "cosas previas" 47 a su poema épico cuando se refiere a que "labran y adornan" con chaquiras su "Ilautos y sus mujeres sus binchos" ${ }^{48}$. El autor de $L a$

\footnotetext{
${ }^{43}$ Ovalle. 1646, Histórica, pp. 52-53.

${ }^{44}$ Valdivia. 1929 [1545 - 1552], Cartas, pp. 204 - 205 (Carta al emperador Carlos V, Concepción, 15 de octubre 1550).

45 Mariño de Lobera. 1865 [1595], Crónica, p. 144.

${ }^{46}$ Vivar. 1966 [1558], Crónica, p. 156.

${ }^{47}$ Cabe señalar que la edición de José Toribio Medina de La Araucana (1910), que usamos aquí, trae una lista más larga de "cosas previas" que la edición de Salamanca de 1574. Confiamos en la erudición del bibliógrafo chileno quien usó la edición de Madrid de 1589 - 1590, supervisada directamente por Ercilla.

${ }^{48}$ Ercilla, Alonso de 1910 [1589 - 1590]. La Araucana. Edición y notas de Medina, José Toribio, Santiago, Imprenta Elzeviriana, p. XIX.
} 
Araucana especifica en qué consistían los llautos usados por los hombres cuando no estaban en combate: "Llauto.- Es un trocho o rodete redondo, ancho de dos dedos, que ponen en la frente y les ciñe la cabeza; son labrados de oro y chaquira, con muchas piedras y dijes en ellos, en los cuales asientan las plumas o penachos, de que ellos son muy amigos; no los traen en la guerra, porque entonces usan celadas." ${ }^{49}$

Es curioso que Ercilla use el término que los incas dieron a aquel tocado, que servía para simbolizar el rango de los altos dignatarios y que permitía, al parecer, reconocer pertenencias étnicas ${ }^{50}$. Cabe preguntarse al respecto: ¿este era el término que le dieron los propios mapuche? No lo sabemos, pero si este fuera el caso estaríamos frente a un préstamo lingüístico y cultural andino de gran trascendencia.

\section{Los mapuche de Concepción, el mundo andino y los inca}

Como ya lo señalamos al inicio de este artículo, los estudios arqueológicos y etnohistóricos más recientes no dejan duda sobre la presencia de elementos culturales y lingüísticos andinos entre los mapuche del periodo prehispánico tardío. Podemos preguntarnos entonces sobre los procesos que dieron origen a estos rasgos y, en particular, tratar de dilucidar cuanto de estas trazas andinas surgieron durante la época inca. Por otra parte, también podríamos interrogarnos sobre las modalidades de trasferencia de estos aportes culturales, por ejemplo, indagar si corresponden a tránsitos indirectos y no intencionados, vía grupos intermedios, o bien a una presencia directa e intencionada del Estado nortino. Todas estas preguntas son difíciles de responder en el estado actual de las investigaciones arqueológicas, por ello cualquier contribución que pueda surgir desde el análisis etnohistórico es a tener en considerar.

En general, no se sabe mucho sobre las dinámicas y permeabilidad de las fronteras incas. Sabemos que el estado inca y las poblaciones bajo su control utilizaron varias técnicas de transferencia de poblaciones dentro y entre los diferentes territorios y fronteras. Esto incumbió diversos niveles de la sociedad, desde la familia extendida que envió a sus familiares a ocupar nuevas tierras hasta los awqa kamayu - "los encargados de la guerra"- enviados por el inca para proteger las fronteras formales del Tawantinsuyu. También sabemos, gracias al trabajo de Renard-Casevitz y Saignes ${ }^{51}$ que una frontera formal andino-amazónica solo existió, en sentido estricto, luego del dominio español bajo el gobierno del virrey Toledo. Además, Parssinnen ${ }^{52}$ ha

\footnotetext{
49 Ibíd., p. XX.

${ }^{50}$ Cobo, Bernabé. 2016 [1653]. Historia del Nuevo Mundo, por el Padre Bernabé Cobo de la Compañía de Jesús. Notas y otras ilustraciones Marco Jiménez de la Espada, Sevilla, Imprenta de E. Rasco, p. 167; Guaman Poma de Ayala. 2013 [1615], El primer nueva, p. 85 y otras.

${ }^{51}$ Renard-Casevitz, France Marie y Saignes, Th. 1986. L'Inca, l'espagnol et les sauvages, Paris, Editions Recherche sur les Civilisations.

52 Parissinen, Martti. 1992. Tawantinsuyu: The Inca State and Its Political Organization, Studia Historica $\mathrm{N}^{\circ} 43$, Helsinky.
} 
sugerido que la frontera sureste del Tawantinsuyu solo se formalizaba en ciertos puntos estratégicos, donde había recintos fortificados. Alrededor de estos enclaves, la frontera se desplazaba con los movimientos de la gente y, en ocasiones, como en el caso de los orejones de Chicha, en el Chaco, simplemente no había puestos fronterizos; más bien el inca saltaba áreas imperfectamente conquistadas para establecer "islas" de control imperial en medio de un vasto espacio de grupos independientes ${ }^{53}$.

Si seguimos la propuesta de Dillehay y Gordon ${ }^{54}$, el interfluvio Itata/Biobío formaba parte informal de la frontera socioeconómica suroccidental del Tawantinsuyu, es decir de un territorio que no alcanzó a estar bajo el dominio político-militar del imperio del norte, pero constituyó un frente de expansión económica y exploración con presencia dispersa de actividad estatal en forma de archipiélago.

Responder a la hipótesis de una presencia inca efectiva en el territorio penquista, dispersa o no, debe considerar el rango de tiempo con que pudieron contar los cusqueños para avanzar hacia el sur desde sus instalaciones de Chile Central. A este respecto, investigaciones recientes están postulando la integración de los valles centrales de Chile al Tawantinsuyo en una época mucho más temprana de lo comúnmente admitido, hacia fines del siglo XIV y principios del XV, sin descartar posibles fechas anteriores ${ }^{55}$. Esta nueva propuesta cronológica, abre un margen temporal de más de 130 años para la expansión de la frontera inca desde los valles centrales hacia el sur de Chile.

Así las cosas, en más de un siglo y ya teniendo bajo control los placeres auríferos de Aconcagua -Marga-Marga, entre otros - y quizás los de las cuencas del Mapocho/Maipo y del Cachapoal/Tinguiririca ${ }^{56}$, bien pudieron los conquistadores incas tener el tiempo suficiente para explorar fuentes auríferas más australes, considerando que la búsqueda del metal dorado era una de las razones -sino la principal- de su expansión en el Collasuyo como bien lo han señalado Raffíno, Gobbo, Lácona y Moralejo ${ }^{57}$.

Cabe señalar que la conquista española del Tawantinsuyu junto con provocar el colapso del imperio del Cusco interrumpió bruscamente su expansión meridional en un momento en que

\footnotetext{
53 Ibídem.

54 Dillehay y Gordon. 1988, “La actividad”, p. 183.

${ }^{55}$ Cornejo, Luis. 2014. "Sobre la cronología del inicio de la imposición cuzqueña en Chile", Estudios Atacameños N 47, p. 113; Uribe y Sánchez. 2016, Los Incas, pp. 567 - 568.

${ }^{56}$ Existen referencias de sitios incas relacionados a lavaderos, a lo menos, en Lampa (Mapocho) y Yaquil (Tinguiririca), (Cuadra, Waldo y Arenas, Marco. 2001. El oro de Chile. Desde los tiempos prehispánicos (900 a.C.) hasta nuestra independencia (1810), Santiago, LOM, p. 55; Raffíno, Rodolfo; Gobbo, Diego; lácona, Anahí y Moralejo, Reinaldo. 2013. La minería y metalurgia de los Inkas del Kollasuyu, Actas del V Congreso Nacional de Arqueología Histórica, Tomo I. Saarbücken, Editorial Académica Española, p. 196. El mapa que elaboró Hugo Contreras con la ubicación de las comunidades indígenas y los asentamientos mineros españoles de Chile central puede proporcionar una representación cartográfica de este espacio de antigua presencia inca. Contreras, Hugo. 2013. "Crisis y cambio en las comunidades nativas del valle de Aconcagua", Población y Sociedad, № 20, vol. 1, Santa Rosa, p. 16.

${ }^{57}$ Raffíno et al. 2013, La minería, p. 190.
} 
posiblemente trataba de imponerse por la fuerza en el área de Concepción. La pérdida del Cusco (1533) debió desarticular sus frentes de conquista y provocar el inicio de la desbandada y repliegue de sus ejércitos y enclaves fronterizos unos diecisiete años antes de que los españoles llegaran de cuerpo presente a Concepción (1550). Durante ese periodo de colapso imperial (1533 -1550), las fuerzas incas debieron enfrentar ofensivas mapuches desde el sur que los hicieron retroceder hasta al río Maule, lugar donde habría ocurrido su derrota definitiva, tal como lo consignaron luego cronistas españoles ${ }^{58}$.

Esa etapa de enfrentamiento con el imperio del norte, seguramente recién se estaba cerrando cuando los españoles llegan a Concepción y tratan de someter a gente entrenada en la guerra contra ejércitos poderosos; de otra manera no se explica el asombro de los españoles al describir la compleja tecnología y estrategia militar de los penquistas.

\section{Quilacoya, su oro y la presencia inca en Concepción}

Las fuentes tempranas que hemos citado más arriba señalan el uso de orfebrería en cobre, oro y plata y la utilización del cobre en la confección de armas entre los mapuche del sur. A este respecto, trabajos arqueológicos han mostrado la presencia de objetos de metal en la Araucanía, al menos a partir del año 1000 d.C. ${ }^{59}$, se trata principalmente de aros de cobre. Sin embargo, no se han encontrado aún evidencias claras que permitan afirmar el origen local de la materia prima de dichos artefactos y de su manufactura, aunque Campbell señala que estos podrían provenir del sector de Lleu-Lleu-Tirúa ${ }^{60}$. Con todo, en el caso del oro, este era abundante en la zona ${ }^{61}$ y su obtención no presentaba mayores dificultades por ser oro aluvial y

\footnotetext{
58 Olavarría. 1852 [1594], “Informe”, pp. 24 - 25.

${ }^{59}$ Campbell, Roberto. 2015. "Entre El Vergel y la platería mapuche: el trabajo de metales en la Araucanía poscontacto (1550-1850 d.C.)", Chungara N 47, Arica, pp. 621 - 644; Dillehay, Tom. 2007. Monuments, Empires, and Resistance, Cambridge, Cambridge University Press; Mera, Rodrigo; Mille, Benoît; Munita, Doina y Figueroa, Valentina. 2015. "Copper earrings in La Araucanía: Earliest evidence of metal usage in Southern Chile", en Latin American Antiquity, $N^{\circ} 26$, Cambridge, pp. 106 - 119.

60 Campbell. 2015, “Entre el vergel”, p. 626.

${ }^{61}$ Flores, Román. 1979. Geología de los depósitos aluviales auríferos de la Cordillera de la Costa-Décima Región, en Actas del Segundo Congreso Geológico Chileno del 6 al 11 de agosto de 1979. Arica, pp. 131 - 147; Greiner, Gerhard. 1991. "Características y distribución de los placeres auríferos de Chile", en Hérail, Gérard y Fornari, Michel (eds.). Gisements alluviaux d'or, La Paz, ORSTOM, pp. 39 - 52; Pincheira, Marcos; Jaramillo, Ernesto y Blanco, Nicolás. 1991. Evaluación preliminar de los placeres auríferos de la VIII región, Concepción, Universidad de Concepción; Portigliati, Carlos; Emparan, Carlos y Vogel, Sonia. 1988. "Los agentes geológicos en la formación de placeres auríferos en el sur de Chile", V Congreso Geológico Chileno, Actas 1. Santiago, pp. A365 - A383; Ruiz, Carlos; Aguirre Le-Bert, Luis; Corvalán, José; Klohn, Carlos; Klohn, Erik y Levi, Beatriz. 1965. Geología y Yacimientos Metaliferos de Chile, Distribución y Génesis de los Yacimientos Metaliferos Chilenos, Santiago, Instituto de Investigaciones Geológicas; Ruiz, Carlos y Peebles, Federico. 1988. Geología, Distribución y Génesis de los Yacimientos Metalíferos Chilenos, Santiago, Editorial Universitaria; Stange, Fredy; Collao, Santiago y Helle, Sonia. 2012. "Posibles fuentes de los placeres auríferos en la Cordillera de la Costa, Región del Bio Bío", XIII Congreso Geológico Chileno. Antofagasta, pp. 58 - 59.
} 
encontrarse generalmente en un estado de pureza que no requería mayor procesamiento por lo que su origen local es lo más probable.

Entre los yacimientos de oro aluvial del interfluvio Itata/Biobío más destacados se encuentran los placeres de Quilacoya ${ }^{62}$. Allí se localizó el más antiguo y uno de los más importantes lavaderos de oro explotado por los españoles durante el siglo XVI (Figura 1). También, las fuentes tempranas señalan otros puntos con presencia de material aurífero en el área, como son el cerro Panicalco, cerca de la actual Florida, ${ }^{63}$ y Tecacurahue, frente a Coelemu ${ }^{64}$.

Quilacoya aparece tempranamente en las fuentes signado como topónimo - nombre de levo-; ya en 1551 era parte de la encomienda de Francisco de Villagra, como se lee en un pleito de encomiendas de 1560:

“Encomiendo en voz Geraldo Gil vecino de la ciudad de la Concepción el 'levo' de 'Quilacoya', Quilquerongo, Quelquengo, Quachumavida, con todos los caciques principales e indios sujetos que tiene asiento cayendo de aquella parte de Biobio que más para servicio de vuestra casa en la dicha ciudad de la Concepción donde voz e vecino entrega de todos los indios comprendidos del cacique Guentande que tienen su tierra pasando de aquella parte del rio Itata hacia la dicha ciudad [...] 1 octubre 1551”65.

Los españoles identificaron desde el principio a Quilacoya como lugar de minas ${ }^{66}$. Con toda la cautela que hay que ejercer en materia de la fijación de la toponimia, etimológicamente la palabra quilacoya se compone de quila que en mapudungun designa la planta Chusquea quila, aunque puede también ser una transcripción aproximada de cüla - numeral cuatro-, y del agregado coya, que no parece pertenecer al léxico del mapudungun, pero sí del quechua. En efecto, coya, en el quechua, significa mina o veta, por lo que se la ha asociado a lugares de extracción de oro y otros minerales ${ }^{67}$. Por lo demás, el término coya se encuentra presente en

\footnotetext{
62 Pincheira et. al. 1991, Evaluación; Stange et al. 2012, Posibles.

${ }^{63}$ Archivo Nacional Histórico de Chile [en adelante ANHCh], Real Audiencia [RA] vol. 599, f. 113v.

${ }^{64}$ ANHCh, Fondo Jesuita [en adelante JES], vol. 8, f. 4.

65 Archivo General de Indias [en adelante AGI], Justicia 403, vol. 2, 1563: fs. 5v-7; el entrecomillado simple es nuestro.

66 Vivar. 1966 [1558], Crónica, p. 169; Góngora Marmolejo. 1982 [1575], Historia, p. 269.

${ }^{67}$ Creemos que puede descartarse la interpretación de algunos autores tardíos de que 'coya' en Quilacoya debe entenderse como 'princesa'. Distinguiendo los dos significados que pudieran haberse confundido al transcribir al castellano, en la última versión del Anónimo (Blas Valera) [1586] de Cerrón, dice: "coya [qhuya] Esparto de las Indias [totora]; coya [qhuya] Mina; coya [quya] Reina, princesa" (Anónimo (Blas Valera). [1586] 2014. Arte, y vocabvlario en la lengva general del Perv llamada quichua, y en la lengua española. Cerrón Palomino, Rodolfo (ed.). Lima, I.R.A./ PUCP, p. 71). Entre corchetes se anota la diversa pronunciación entre qhuya y quya. Más claro está en el Vocabulario de González Holguín: "Koya: Ichu largo correoso como esparto; Koya. Veta de la mina" (González Holguín, Diego. 1989 [1608]. Vocabulario de la Lengva General de todo el Perv llamada Lengva Qquichua o del Inca, Lima, Imprenta de Francisco del Canto, p. 142), y “Ccoya. Reyna o princessa heredera” (González Holguín. 1989 [1608], Vocabulario, p. 70). Igualmente, el Vocabulario de Bertonio distingue entre ccoya: mina o socavón, y coya: mujer principal, reina (Bertonio, Ludovico. 1612. Vocabulario de la lengua aymara. Juli; Provincia de Chucuito, Perú, Casa de la Compañía
} 
varios topónimos asociados a minas o vetas mineralógicas de norte y centro de Chile - área confirmada de dominio inca - pero también más al sur, evidentemente en Quilacoya Concepción-, pero también en Osorno - a 500 km del Biobío - en Millacoya ${ }^{68}$, topónimo que en español querría decir "mina (coya) de oro (milla)". En la tabla 1 identificamos los yacimientos mineros de Chile que contienen el vocablo coya.

Tabla 1: Yacimientos mineros de Chile cuyos topónimos incluyen la voz quechua coya ${ }^{69}$

\begin{tabular}{|c|c|c|c|}
\hline Áreas & Topónimo & Tipo de mineral & Localización \\
\hline \multirow{3}{*}{$\begin{array}{c}\text { Bajo control } \\
\text { Inca }\end{array}$} & Yarvicoya & Cobre, plomo y plata & Pozo Almonte, Iquique \\
\hline & Antucoya & Cobre & María Elena, Antofagasta \\
\hline & Coya & Cobre & Machalí, Cachapoal \\
\hline \multirow{3}{*}{ Mapuche } & Collas (cajón de) & Cobre, plomo y plata & Curicó \\
\hline & Quilacoya & Oro & Hualqui, Concepción \\
\hline & Millacoya & Oro & Río Negro, Osorno \\
\hline
\end{tabular}

Fuente: elaboración propia.

En vista de la temprana e importante presencia de quechuismos en el mapudungun ${ }^{70} \mathrm{y}$ considerando que el término coya sirvió para denominar yacimientos mineros en toda el área donde el quechua fue lengua de los conquistadores, es muy probable que el topónimo Quilacoya sea una palabra compuesta mapudungun/quechua preexistente a la presencia española, puesto que de otro modo no se explicaría su temprana y general adopción en las fuentes coloniales. Por lo tanto, si Quilacoya es un topónimo compuesto donde el significante más importante coya es quechua, quienes lo bautizaron de esa manera dominaban esa lengua y lo hicieron porque allí había oro ${ }^{71}$.

de Jesús por Francisco del Canto, pp. 317-553). Ver un análisis detallado sobre el tema en "Indagaciones..." de Payàs y Villena.

68 Flores. 1979, “Geología”, p. 9; Lagos, Ramiro y Vahí, Amalia. 2011. “Cartografía colonial de Osorno: los mapas de Miguel María de Atero, 1804", en Espacio Regional №2, vol.8, Osorno, p. 34.

69 Armengol, Pedro. 1918. Glosario Etimológico de Nombres de Hombres, Animales, Plantas, Ríos y Lugares, y de vocablos incorporados en el Lenguaje Vulgar, aborígenes de Chile, y de algún otro país americano, Santiago, Imprenta Universitaria, p. 148; Flores. 1979, "Geología"; Fuenzalida, Alejandro. 1919. "El trabajo i la vida en el Mineral "El Teniente'”, Boletín Minero N²242, p. 271; Lagos y Vahí. 2011, “Cartografía”, p. 34; Latrille, Francisco. 1896. "Informe de los minerales de Yabricoya i Jauja espedido por el injeniero de Minas Don Francisco Latrille, en marzo, 12 de 1892", Boletín de la Sociedad Nacional de Minería, № 90, Santiago, p. 70; Moreno, Teresa y Gibbon, Wes. 2007. The Geology of Chile. Londres, Geological Society, p. 184; Riso Patron, Luis. 1924. Diccionario jeográfico de Chile, Santiago, Imprenta Universitaria; Servicio Nacional de Geología y Minería, SERNAGEOMIN. 2014. Sistema de información de yacimientos minerales de Chile, ficha $N^{\circ} 3202$, Yabricoya, Santiago.

70 Sánchez, Gilberto. 2014. "Los quechuismos en el mapuche (mapudungun(n)), antiguo y moderno, de Chile", IX Congreso Internacional de Lexicología y Lexicografía en homenaje a Enrique Carrión Ordóñez, Lima.

${ }^{71}$ La presencia de quechuismos o aimarismos en el léxico de la minería y metalurgia que recoge Lenz en su Diccionario Etimológico del español de Chile (chacra, apir, sirca, pirca y, desde luego, tupu) es testimonio del influjo del quechua o aimara en el vocabulario especializado minero-metalúrgico del castellano y del mapudungun. Es digno 
La hipótesis de una presencia inca hasta el Biobío, específicamente en Quilacoya, encuentra respaldo etnohistórico en las palabras del jesuita Diego de Rosales, cronista serio y bien informado que escribió, eso sí, alrededor de un siglo después de la conquista española de Penco. En su crónica, este afirma que los incas habrían levantado dos fuertes sobre el río Itata y avanzado hasta Quilacoya, en tierras de Quinchatipai, donde habrían instalado otro fuerte y unos promontorios ceremoniales, dice:

"Pasaron [los incas] adelante a la Angostura y Maule, como se ve por las memorias que todavía duran de los fuertes que hizieron, y en los promaucaes fueron rotos, desbaratados de los indios de Chile, y embiando por mas gente al Perú volvieron a proseguir la conquista hasta llegar a 'Itata, donde ay otros dos fuertes, y en Culacoya' prosiguiendo con su conquista en tierras del Gran Señor Quinchatipai, cinco leguas de la ciudad de Concepción, 'tuvieron otra fortaleza', y allí 'ay siete piedras a manera de pirámides labradas que fueron puestas por los indios del Perú para hacer la ceremonia llamada Calpa Inga, que se hacia para la salud del Rey Inga cada año'"172.

Las afirmaciones de Rosales sobre una fortaleza y siete piedras a manera de pirámides que existirían en Quilacoya - Culacoya, escribe él-, donde los incas habrían hecho sus ceremonias -el Calpa Inga, de acuerdo con la crónica- constituyen la afirmación más explícita y evidente de un dominio inca hasta el Biobío.

Dicho lo anterior, no es posible ratificar hasta ahora que este complejo ceremonial inca haya existido, aunque se ha popularizado la idea de que el lugar al cual se refiere Rosales corresponde al cerro de la Piedra con Costilla, en Hualqui, vecino a Quilacoya ${ }^{73}$. Efectivamente, en la cima de esta montaña de la Cordillera de la Costa -a $313 \mathrm{msnm}$ - se encuentran efloraciones rocosas amesetadas desde las cuales se pueden visualizar los meandros inmediatos al estuario del Biobío. El sitio presenta registro arqueológico, sin asignación cronológica, de arte rupestre, distribuido en tres bloques grabados de surco profundo y donde destaca el diseño de un rostro antropomorfo ${ }^{74}$.

Mucho antes que Rosales, en 1594, Miguel de Olavarría ya afirmaba que los incas habían llegado hasta el Biobío, basándose en testimonios de ancianos y en su propia observación de

de observarse que los numerales quechua pataka (cien) y waranka (mil), así como la palabra que indica la acción y resultado de marcar, rayar, inscribir o escribir (chillka) pasaron al mapudungun en circunstancias que no están esclarecidas pero que pueden asociarse precisamente a actividades económicas derivadas de estos contactos.

72 Rosales. 1877 [1674], Historia, p. 339; el entrecomillado simple es nuestro.

${ }^{73}$ Espinoza Olivares, Luis. 2018. La Ruta del oro en la antigua frontera del Biobío, Concepción, Ediciones del Archivo Histórico de Concepción, p. 38.

${ }^{74}$ Campbell, Roberto; Moya Cañoles, Francisca y Gutiérrez, Renata. 2020. “Quien busca, encuentra. Arte rupestre en el sur de Chile: Evaluación, perspectivas y preguntas", en Boletín del Museo Chileno de Arte Precolombino, № 25, 1, Santiago, pp. 252 - 256. 
terreno ${ }^{75}$. Este autor señala que, antes del repliegue inca al norte del río Maule que antecedió su retirada de Chile traspasando los Andes, estos alcanzaron el Biobío:

"Entrada esta gente en Chile [los incas] después de haverles dado muchas batallas y hecho y recibido grande estrago conquistaron y subjetaron todos los indios que avía desde la Serena 'asta el gran río de Biobío' como 'oy se ve e aver llegado hasta el dicho río por los fuertes que hicieron en el cerro del río claro' donde pusieron y tuvieron frontera a los indios del estado con quienes tuvieron muchas batallas, alfin estos indios belicosos aunque no eran tan diestros como ahora ayudados de su muchedumbre que entonces tenían hicieron retirar y desamparar todo lo que avían ganado a los Indios del Pirú y llegaron a su alcance hasta el río de Maule donde 'según noticias que dan los indios de mucha edad' que algunos vivían tres años y medio a de quienes yo fui informado y en los llanos que están cerca del dicho río tuvieron/ los unos y los otros una sangrienta batalla en que mataron a la mayor parte de los del Perú y los que quedaron así por huir su furia como 'por aver tenido noticia que en este tiempo habían entrado Españoles en el Perú y prendieron a su Rey', es cierto que traspusieron y pasaron la gran cordillera por el río de Butagan que está cerca del dicho río de Maule"76.

Concordando con las afirmaciones de Olavarría y Rosales, traemos a colación un testimonio inédito. Se trata de la declaración del anciano indígena Alonso Guerillengue de Cobquecura, sector costero del área norte del río Itata (Figura 1), quien en 1625 declara haber conocido a los incas cuando estos entraron a conquistar, antes del arribo de los españoles:

“Indio Alonso Guerillengue más de 100 años de edad [...] dijo llamarse Alonso Guerillengue y ser natural del pueblo de Codquicura de la encomienda del dicho capitán don Fernando Alarcon [...] dijo que 'cuando los españoles entraron en el reino era ya casado que según la cuenta son mas de ciento y tanto años' [...] este testigo conoció al padre de este Guenulebo que se refiere la pregunta que fue el tatarabuelo de los dichos indios aquí [...] y que la mujer de este Guenulebo Antequi su viuda se vino del pueblo de Buidaguida al pueblo de Codquicura y tierrras Ilamadas Gialda la cual vino preñada y allí pario al Guanulebo primero de este nombre bisabuelo de los dichos tres indios el cual nacido en la dichas tierras Ilamadas Chidas y 'que cuando nació no habían entrado en el reino los primeros españoles que en aquel ocasión conoció este testigo a los inga que habían venido a este reino a conquistar le'

\footnotetext{
75 Nos referimos principalmente al señalamiento que da el autor cuando dice: "como oy se ve" refiriéndose a restos de "fuertes" en el cerro del río Claro. Una Merced de Tierra de 1606 también hace referencia a un "fuerte viejo" a orillas del río Claro: "dijo tener necesidad de seiscientas quadras de tierras para en que tener sus ganados y hacer una estancia en que poder sembrar las quales son orillas del rio Claro medio legua el rio arriba mas alla del fuerte viejo en la parte que el suso las señalase", ANHCh, RA vol. 2781, 1606: f. 151; el entrecomillado simple es nuestro. 76 Olavarría. 1852 [1594], "Informe", pp. 24 - 25; el entrecomillado simple es nuestro.
} 
y este testigo vio que el dicho Guenulebo residio en las tierras llamada Leguida que eran suyas y allí se caso y tuvo hijos de cuya sepa desenden los dichos indios"77.

Se podría cuestionar, en este testimonio, que la longevidad de Alonso Guerillengue está exagerada, pero incluso disminuyendo la edad del anciano a una cifra bajo los 100 años, la cronología de los hechos que describe es coherente. En efecto, si Guerillengue estaba casado cuando los españoles "entraron al reino" -como declara- puede estar refiriéndose a la conquista de la provincia de Penco (1550), acontecimiento que lo pudo afectar más directamente. Si esto fuera así, Alonso Guerillengue podría haber nacido al inicio de la década de 1530 y haber conocido a los incas en su niñez.

\section{La voz inga (inca) en la toponimia y antroponimia de Concepción}

Retomando lo señalado por Rosales respecto a un sitio ceremonial inca en las inmediaciones de Quilacoya y la asociación que se puede hacer con el actual cerro de la Piedra con Costilla de Hualqui, resulta interesante adicionar un testimonio inédito del siglo XVII que entrega el topónimo de un cerro de Hualqui que servía como referente para deslindes y que contiene la voz inca; se trata de la solicitud de merced de tierras de Gaspar Martínez del 22 de enero de 1675:

“[...] hacerle merced de 500 cuadras de tierras a vista de Gualque que están vacas por fin y muerte de los indios de aquellos parajes que antiguamente era de Taruante y Lecanante caciques y de sus sujetos difuntos que tienen por linderos el cerro de Pengoy Labquen y el estero de Elol y el cerro de 'Ingadunado' que está a la vista del dicho Gualque...Concepción 22 enero $1675[\ldots]^{\prime \prime 78}$.

Claramente el topónimo Ingadunado o Ingadanudu hace alusión en su raíz a inca -inga en las fuentes de la época- y sospechamos que el sufijo do o du puede ser una deformación de we o hue, sufijo que en la toponimia mapuche es un designativo de "lugar"; más difícil de interpretar resulta el morfema intermedio duna o danu ${ }^{79}$.

No es el único caso en que inga se encuentra en la toponimia y antroponimia temprana de Concepción. Así, por ejemplo, en un sector ribereño al Biobío, donde actualmente se encuentra la zona urbana de la ciudad y la actual comuna de Hualpén, aparece la denominación Ingagueno o Ingaygueno. En esta ocasión, se trata de una merced de tierra concedida, en 1605, a Pedro

\footnotetext{
77 ANHCh, RA, vol. 1738, 1625: pza. 1; el entrecomillado simple es nuestro.

${ }^{78}$ ANHCh, Capitanía General [ en adelante CG], vol. 477, 1675: f. 105v; el entrecomillado simple es nuestro.

79 Una posibilidad sería que duna/danu tuviera que ver con el vocablo duamn siguiendo la interpretación que da Armengol para el topónimo Duao (Armengol. 1918, Glosario, p. 288). Según este autor, duamn hace referencia a pensamiento, recuerdo, lo que para el caso de Ingadunado podría ser algo como "El lugar donde hay recuerdo del Inca". Desde luego, en materia de toponimia, cuando hay lenguas en contacto, son significativas las dificultades de atribución. Por ahora no podemos sino proponer y esperar que surjan estudios más especializados.
} 
Páez Castillejo, instancia en que se hizo referencia al curaca Ingagueno ${ }^{80}$ y al "asiento" Ingaygueno en la toma de posesión de ella:

“[...] hago merced a vos el dicho capitán don Pedro Páez Castillejo de mil cuadras de tierras en la ciudad de la Concepción que corren desde el fuerte de San Pedro hasta el rio de Chepe rio arriba que eran del 'curaca Ingagueno' [...]. Posecion: en la ciudad de la Concepcion en 15 dias del mes de marzo de 1605 [...] en el 'asiento de Ingaygueno' junto al fuerte de San Pedro rio de Biobio arriba" 81 .

En esta merced, además, aparece especificado el rango de curaca, que como sabemos era la denominación que daban los incas a los jefes locales. Es cierto que el término curaca fue utilizado por los españoles como genérico para referirse a cualquier líder local, pero en el caso del sur de Chile su uso no fue muy frecuente. Con todo, el término curaca figura también como designación de rango en otros dos casos tempranos ubicados en la provincia de Concepción: para designar al cacique principal de la Encomienda de Tomeco, en $1579^{82}$ y en referencia a un jefe indígena de la ribera de la Laja, en el Juicio de residencia de Quiñones de $1599^{83}$.

Para finalizar este apartado respecto a la voz inca, cabe señalar que lo evidente muchas veces no llama la atención y es justamente lo que pasa con la denominación que los habitantes de la provincia de Concepción dieron a los conquistadores españoles al momento de su llegada: ingas. Este calificativo perdura hasta la actualidad en el mapudungun como parte de la palabra wingka (we-inka: nuevo inca) y sirve para denominar al no mapuche. Fueron los mapuche de Penco quienes bautizaron así a los españoles como claramente lo expresa Pedro de Valdivia al referir a Carlos V su nueva conquista: "Llámannos a nosotros ingas, y a nuestros caballos hueque ingas, que quiere decir ovejas de ingas" ${ }^{84}$. Resulta evidente entonces que, desde el primer encuentro, los penquistas asociaron a los nuevos conquistadores con aquellos que ya conocían con anterioridad: los incas.

\section{Conclusión}

Las investigaciones arqueológicas en el área situada entre los ríos Maule y Biobío son todavía escasas, por lo que no permiten confirmar o descartar una presencia efectiva del Tawantinsuyu en dicho territorio. Sin embargo, las fuentes escritas, iconográficas y toponímicas que hemos presentado nos proporcionan una serie de indicios que, mirados en su conjunto, y aun considerando la posibilidad de sesgos y de transcripciones o atribuciones erróneas, autorizan a

\footnotetext{
80 Gueno (wenu): cielo o "lo de arriba" en mapudungun.

${ }^{81}$ ANHCh, RA, vol. 2319, 1605: f. 185. El entrecomillado simple es nuestro.

82 ANHCh, RA, vol. 2435, 1579: f. 36.

83 ANHCh, RA, vol. 1643, 1599: f. 56.

${ }^{84}$ Valdivia. 1929 [1545 - 1552], Cartas, p. 205 (Carta al emperador Carlos V, Concepción, 15 de octubre 1550).
} 
sostener como muy probable una presencia, quizás corta y no consolidada, de los incas hasta el río Biobío.

Como lo hemos expresado en las páginas anteriores, el carácter guerrero y la logística militar de los mapuche de Penco, así como el desarrollo agrícola y ganadero que muestran al primer contacto con los españoles, dejan entrever una dinámica prehispánica que se vuelve más comprensible si se considera un cierto grado de interacción con el imperio del norte.

Por otra parte, la importancia que tuvieron en el siglo XVI español los lavaderos de oro de Concepción -Quilacoya-, que incluso tomaron el relevo de los de Aconcagua -MargaMarga- que ya habían sido explotados por los incas hacen plausible una exploración cusqueña de estos placeres auríferos. Al respecto, es preciso considerar, por un lado, la rapidez con que fueron descubiertos dichos lavaderos por los nuevos conquistadores peninsulares, y, por otro, que el topónimo que los identifica contiene la palabra quechua para mina: coya.

Como hemos visto, dos observadores de terreno, atentos e informados, Miguel de Olavarría y Diego de Rosales, señalaron -el uno en 1594 y el otro a mediados del siglo XVII- la existencia de restos constructivos y noticias indígenas sobre la presencia inca en Concepción. A lo anterior, pudimos adicionar el testimonio inédito del anciano indígena Alonso Guerillengue y varias referencias tempranas, igualmente inéditas, del área de Concepción sobre topónimos y antropónimos que contienen la palabra inga igualmente usada en el etnónimo que los penquistas dieron a los españoles: ingas.

Por último, cabe reiterar el hecho de que estudios arqueológicos recientes estén considerando fechas cada vez más tempranas para la implantación del Tawantinsuyu en Chile Central, lo que permite ampliar el marco temporal del frente de conquista suroccidental del imperio. De acuerdo con esta nueva cronología, los incas habrían tenido más de un siglo para afianzar su conquista en los valles centrales y, de ese modo, avanzar hacia el sur.

Sin duda, son necesarias aún más investigaciones que permitan dilucidar con mayor nitidez las relaciones de los mapuche del sur con el mundo andino, determinar con mayor precisión los momentos, los procesos y los factores que incidieron durante varios siglos anteriores al arribo español en las configuraciones culturales con las que estos se encontraron en las tierras meridionales y que sin duda continuaron en el contexto colonial. Para ello se requieren más investigaciones arqueológicas, en particular sobre el área intermedia situada entre los ríos Maule y Biobío. Por otra parte, los estudios de lingüística comparada pueden aportar aún más luces sobre las relaciones entre el mapudungun y las lenguas del área andina. Del mismo modo, es necesario hacer avances en los incipientes estudios de toponimia puesto que los nombres de los lugares son marcas culturales profundas inscritas en el territorio. Este artículo es solo un aporte limitado pero entusiasta que se inscribe en esta senda de investigación interdisciplinaria. 


\section{Referencias citadas}

\section{Archivos}

Archivo General de las Indias (AGI):

- Fondo Justicia (Justicia): Legajo 403.

Archivo Nacional Histórico de Chile (ANHCh):

- Fondo Capitanía General de Chile (CG): volumen 477.

- Fondo Jesuitas (JES): volumen 8.

- Fondo Real Audiencia (RA): volúmenes 1643, 1738, 2319, 2435, 2781.

\section{Bibliografía}

Adán, Leonor, Mera, Rodrigo, Navarro, Ximena, Campbell, Roberto, Quiroz, Daniel y Marco Sánchez. 2016. "Historia prehispánica en la región Centro-Sur de Chile: Cazadores-recolectores holocénicos y comunidades alfareras (ca. 10.000 a.C. a 1.550 años d.C.) en Falabella, Fernanda y otros (Eds.) Prehistoria en Chile. Desde sus primeros habitantes hasta los Incas, Santiago, Editorial Universitaria, pp. 401-441.

Ajens, Andrés. 2017. "Conexiones huilliche-altoperuanas en el ciclo de Atahualpa”, en Meridional, $\mathrm{N}^{\circ}$ 8, Santiago, pp. 153-188.

Anónimo (Blas Valera). (1586) 2014. Arte, y vocabvlario en la lengva general del Perv llamada quichua, y en la lengua española, Cerrón Palomino, Rodolfo (ed.), Lima, I.R.A./PUCP.

Andrade, Pedro, Silva, Francisco, Mengozzi, Francesca, Urzúa, Paula, Campbell, Roberto y Hernández, Javier. 2012. "Influencias incaicas más allá del Cachapoal: el caso del sitio Palquibudi, cuenca media del río Mataquito", en Actas del XVIII Congreso Nacional de Arqueología Chilena, Congreso organizado por la Sociedad Chilena de Arqueología, Santiago, pp. 341-350.

Armengol, Pedro. 1918. Glosario Etimológico de Nombres de Hombres, Animales, Plantas, Ríos y Lugares, y de vocablos incorporados en el Lenguaje Vulgar, aborígenes de Chile, y de algún otro país americano, Santiago, Imprenta Universitaria.

Bahamondes, Francisco. 2007. "Las sociedades prehispánicas tardías y coloniales de La Araucanía: la cerámica bícroma como elemento de continuidad sociocultural (S.X-XVIII D.C.)", en VI Congreso Chileno de Antropología (Valdivia), Tomo 2 (1919-1931). Congreso llevado a cabo por el Colegio de Antropólogos de Chile, Santiago, pp. 1918-1931.

Bahamondes, Francisco. 2009. La cerámica prehispánica tardía de Araucanía septentrional: el complejo arqueológico El Vergel y su relación con la hipótesis del proceso de andinización. Universidad de Chile, Memoria para optar al título profesional de Arqueólogo. 
Bahamondes, Francisco. 2010. “Las poblaciones tardías de Araucanía Septentrional: el complejo El Vergel y su relación con el proceso de andinización", en Actas del XVII Congreso Nacional de Arqueología Chilena. Congreso organizado por la Sociedad Chilena de Arqueología, Santiago, pp.452-461.

Bahamondes, Francisco, Silva, Claudia y Campbell, Roberto. 2006. "La Candelaria: un yacimiento funerario del complejo El Vergel en el curso inferior del río Bío-Bío”, en Boletín de la Sociedad Chilena de Arqueología, №39, Santiago, pp. 69-85.

Berenguer, José. 2013. "Unkus ajedrezados en el arte rupestre del sur del Tawantinsuyu: ¿La estrecha camiseta de la nueva servidumbre?", en Albeck, María Ester, Ruiz, Marta y Cremonte, Beatriz (eds.), Las tierras altas del Área Centro Sur Andina entre el 1000 y el 1600 d.C. TANOA II. Taller Internacional de Arqueología del Noroeste Argentino y Andes Centro Sur, Argentina, Juju: EdiuNJu, pp. 311-352.

Bertonio, Ludovico. 1612. Vocabulario de la lengua aymara, Juli, Chucuito-Perú, Casa de la Compañía de Jesús por Francisco del Canto.

Betanzos, Juan de. 2015 (1551-1558). Suma y Narración de los Incas. Edición de Hernández Astete, Francisco y Cerrón-Palomino, Rodolfo, Lima, Pontificia Universidad Católica del Perú.

Campbell, Roberto. 2004. El trabajo de los metales en la Araucanía (siglos X a XVII d.C.), Universidad de Chile, Memoria para optar al título de Arqueólogo.

Campbell, Roberto. 2015. "Entre El Vergel y la platería mapuche: el trabajo de metales en la Araucanía poscontacto (1550-1850 d.C.)”, en Chungara N 47, Tarapacá, pp. 621-644.

Campbell, Roberto, Moya Cañoles, Francisca y Gutiérrez, Renata. 2020. “Quien busca, encuentra. Arte rupestre en el sur de Chile: Evaluación, perspectivas y preguntas", en Boletín del Museo Chileno de Arte Precolombino, N²5, 1, Santiago, pp. 252-256.

Cobo, Bernabé. 2016 (1653). Historia del Nuevo Mundo, por el Padre Bernabé Cobo de la Compañía de Jesús. Notas y otras ilustraciones Marco Jiménez de la Espada, Sevilla, Imprenta de E. Rasco.

Contreras, Hugo. 2013. "Crisis y cambio en las comunidades nativas del valle de Aconcagua", en Población y Sociedad, N²0, 1, Santa Rosa - La Pampa, pp. 11 - 40.

Cornejo, Luis. 2014. "Sobre la cronología del inicio de la imposición cuzqueña en Chile", en Estudios Atacameños, № 47, San Pedro de Atacama, pp. 101-116.

Cornejo, Luis. 2018. "El centro político inka en el extremo austral del Tawantinsuyu (Chile Central)", en Boletín del Museo Chileno de Arte Precolombino, № 23, 1, Santiago, pp. 133-158.

Cuadra, Waldo y Marco Arenas. 2001. El oro de Chile. Desde los tiempos prehispánicos (900 a.C.) hasta nuestra independencia (1810), Santiago, LOM.

Dillehay, Tom. 1990. "El Formativo del Extremo Sur de Chile", en Gaceta Arqueológica Andina, N 17, Lima, pp. 101-114.

Dillehay, Tom y Gordon, Américo. 1988. "La actividad prehispánica de los incas y su influencia en La Araucanía", en Dillehay, Tom y Netherly, Patricia (eds.). La Frontera del Estado Inca, Quito, Fundación Alexander Von Humboldt y Editorial Abya Yala, pp. 183-197. 
Dillehay, Tom. 2011. Monumentos, Imperios y Resistencia en Los Andes: El Sistema de Gobierno Mapuche y Las Narrativas Rituales, Antofagasta, Imprenta Qillqa y Universidad Católica del Norte.

Dillehay, Tom. 2020. Montículos "vivientes", imperios y resistencias en los Andes. Narrativas rituales del esapcio y gobierno mapuche, Antofagasta, Imprenta Qillqa y Universidad Católica del Norte. León Echaíz, René. 1957. Prehistoria de Chile central, Talca, Poblete.

Ercilla, Alonso de. 1574. La Araucana, Salamanca, Casa de Domingo de Portonarijs.

Ercilla, Alonso de. 1910 (1589-1590). La Araucana, Toribio Medina, José (ed.). Santiago, Imprenta Elzeviriana.

Espinoza Olivares, Luis. 2018. La Ruta del oro en la antigua frontera del Biobío, Concepción, Ediciones del Archivo Histórico de Concepción.

Flores, Román. 1979. "Geología de los depósitos aluviales auríferos de la Cordillera de la CostaDécima Región", en Actas del Segundo Congreso Geológico Chileno del 6 al 11 de agosto de 1979, Arica, pp. 131-147.

Fuenzalida, Alejandro. 1919. "El trabajo i la vida en el Mineral 'El Teniente”", en Boletín Minero N 242, Santiago, pp. 271-350.

Guaman Poma de Ayala, Felipe. 2013 (1615). El primer nueva crónica y buen gobierno por Felipe Guaman Poma de Ayala. Murra, John V. y Adorno, Rolena (eds.), México, Siglo XXI. Góngora Marmolejo, Alonso de. 1862 (1575). Historia de Chile desde su descubrimiento hasta el año de 1575. Colección de Historiadores de Chile, Tomo 2, Santiago, Imprenta del Ferrocarril.

Greiner, Gerhard. 1991. "Características y distribución de los placeres auríferos de Chile", en Hérail, Gérard y Fornari, Michel (eds.). Gisements alluviaux d'or, La Paz, ORSTOM, pp. 39-52 Guevara, Tomás. 1908. Psicolojia del pueblo araucano, Santiago, Imprenta Cervantes. Guevara, Tomás. 1925. Chile prehispano, Santiago, Universidad de Chile.

Gusinde, Martín. 1916. "Medicina e higiene de los antiguos araucanos", en Congreso Católico Araucanista de Santiago, Santiago, Publicaciones del Museo de Etnología y Antropología, pp. 87121.

González de Holguín, Diego. 1989 (1608). Vocabulario de la Lengva General de todo el Perv llamada Lengva Qquichua o del Inca, Lima, Imprenta de Francisco del Canto.

Pincheira, Marcos, Jaramillo, Ernesto y Blanco, Nicolás. 1991. Evaluación preliminar de los placeres auríferos de la VIII región, Concepción, Universidad de Concepción.

Inostroza, Iván. 2013. "La colonización minera y agrícola en la ciudad Imperial del Sur de Chile: 1551-

1561", en Revista Complutense de Historia Americana, Vol. 39, Madrid, pp. 107-127.

Keller, Carlos. 1960. Los orígenes de Quillota, Santiago, Editorial Universidad Católica.

Lagos, Ramiro y Vahí, Amalia. 2011. "Cartografía colonial de Osorno: los mapas de Miguel María de Atero, 1804", en Espacio Regional № 2, 8, Osorno, pp. 25-36.

Latcham, Ricardo. 1908. “¿Hasta dónde alcanzó el dominio efectivo de los Incas en Chile?”, en Revista Chilena de Historia Natural, Nº12, 4, Santiago, pp. 178-199. 
Latcham, Ricardo. 1924. "La organización social y creencias religiosas de los antiguos araucanos", en

Publicaciones del Museo de Etnología y Antropología Tomo III, Santiago, Imprenta Cervantes, pp. 245-868.

Latrille, Francisco. 1896. "Informe de los minerales de Yabricoya i Jauja espedido por el injeniero de Minas Don Francisco Latrille, en marzo, 12 de 1892", en Boletín de la Sociedad Nacional de Minería, N 90, Santiago, pp. 70-74.

León, Leonardo. 1983. “Expansión inca y resistencia indígena en Chile, 1470-1536”, en Chungará, № 10, Arica, pp. 95-115.

Mariño de Lobera, Pedro. 1865 (1595). Crónica del reino de Chile, Colección de Historiadores de Chile, Tomo 6, Santiago, Imprenta del Ferrocarril.

Medina, José Toribio. 1882. Los aboríjenes de Chile, Santiago, Gutenberg.

Mera, Rodrigo; Mille, Benoît, Munita, Doina y Figueroa, Valentina. 2015. "Copper earrings in La Araucanía: Earliest evidence of metal usage in Southern Chile", en Latin American Antiquity, $N^{\circ}$ 26, Cambridge, pp. 106-119.

Moreno, Teresa y Gibbon, Wes. 2007. The Geology of Chile, Londres, Geological Society.

Moulian, Rodrigo y Catrileo, María. 2013. "Kamaska, kamarikun y müchulla: préstamos lingüísticos y encrucijadas de sentido en el espacio centro y sur andino", en Alpha $\mathrm{N}^{\circ} 37$, Osorno, pp. 249263.

Moulian, Rodrigo y Espinoza, Pablo. 2015. "Impronta andina entre los Kamaskos del Wenuleufu", en Atenea, $\mathrm{N}^{\circ}$ 512, Concepción, pp. 311-230.

Moulian, Rodrigo; Latorre, Elvira; Caniguan, Jaqueline y Bahamondes, Francisco. 2020. "Pañilwe ñi dungu: las voces del metal", en Revista Antropologías del Sur N 7, 13, Santiago, pp. 1-25.

Ocaña, Diego de. 1995 (1600-1607). Viaje a Chile: Relación del viaje a Chile, año de 1600, contenida en la crónica de viaje intitulada "A través de la América del Sur". Introducción y notas de Eugenio Pereira Salas, Santiago, Editorial Universitaria.

Olavarría, Miguel de. 1852 (1594). "Informe de Don Miguel de Olavarría sobre el Reyno de Chile, sus indios y sus guerras (1954)", en Gay, Claudio (comp.), Historia Física y Política de Chile: Documentos sobre la Historia, la Estadística y la Geografía de Chile, Tomo 2, París, Casa del Autor, pp. 13-54.

Ovalle, Alonso de. 1646. Histórica relación del Reyno de Chile, Roma, Francisco Caballo.

Parissinen, Martti. 1992. Tawantinsuyu: the Inca State and Its Political Organization, Helsinki, Societas Historica Finlandiae, Studia Historica, $\mathrm{N}^{\circ} 43$.

Payàs, Gertrudis y Villena, Belén. 2021. "Indagaciones en torno al significado del oro en la cultura mapuche. Una exploración de fuentes”, en Estudios Atacameños, № 67, San Pedro de Atacama, e-4253.

Peña, Beatriz. 2011. Imagenes contra el olvido: El Perú colonial en las ilustraciones de fray Diego de Ocaña, Lima, Fondo Editorial de la Pontificia Universidad Católica del Perú.

Peña, Beatriz. 2016. Fray Diego de Ocaña: olvido, mentira y memoria, Alicante, Publicaciones de la Universidad de Alicante. 
Pereira Salas, Eugenio. 1995. "Introducción y notas", en Ocaña, Diego de, Viaje a Chile: Relación del viaje a Chile, año de 1600, contenida en la crónica de viaje intitulada "A través de la América del Sur", Santiago, Editorial Universitaria, pp.15-27.

Planella, María Teresa y Stehberg, Rubén. 1994. "Etnohistoria y arqueología en el estudio de la fortaleza indígena de cerro grande de la Compañía”, en Chungará, № 26, Arica, pp. 65-78.

Planella, María Teresa, Stehberg, Rubén, Niemeyer, Hans, Tagle, Blanca y del Río, Carmen. 1993. "La fortaleza indígena del Cerro Grande de La Compañía (valle del Cachapoal) y su relación con el proceso expansivo meridional incaico", en Actas del XII Congreso Nacional de Arqueología Chilena (Temuco 1991) / Boletín del Museo Regional de la Araucanía, Tomo II. Temuco, Ediciones de la Dirección de Bibliotecas, Archivos y Museos, pp. 403-421.

Raffíno, Rodolfo, Gobbo, Diego, lácona, Anahí y Moralejo, Reinaldo. 2013. "La minería y metalurgia de los Inkas del Kollasuyu", en Actas del V Congreso Nacional de Arqueología Histórica, Tomo 1. Saarbücken, Editorial Académica Española, pp. 187-216.

Renard-Casevitz, France Marie y Saignes, Th. 1986. L'Inca, l'espagnol et les sauvages, París, Editions Recherche sur les Civilisations.

Riso Patron, Luis. 1924. Diccionario jeográfico de Chile, Santiago, Imprenta Universitaria.

Rivera, Mario A., y Hyslop, John. 1984. "Algunas estrategias para el estudio del camino del inca en la región de Santiago, Chile", en Cuadernos de Historia, № 4, Santiago, pp. 109-128.

Rosales, Diego de. 2018 (1674). Historia General de el Reyno de Chile, Flandes Indiano, Vicuña Mackenna, Benjamín (ed.), Valparaíso, Imprenta del Mercurio, Forgotten Books, pp. 191-197.

Rosales, Diego de. 1877 (1674). “Historia General de el Reyno de Chile, Flandes Indiano”, Vicuña Mackenna, Benjamín (ed.). Valparaíso, Imprenta del Mercurio.

Ruiz, Carlos y Peebles, Federico. 1988. Geología, distribución y génesis de los yacimientos metalíferos chilenos, Santiago, Editorial Universitaria.

Sánchez, Rodrigo. 2004. "El Tawantinsuyu en Aconcagua (Chile central)”, en Chungará, N 36, 2, Arica, pp. 325-336.

Sánchez, Gilberto. 2014. "Los quechuismos en el mapuche (mapudungun(n)), antiguo y moderno, de Chile", en IX Congreso Internacional de Lexicología y Lexicografía en homenaje a Enrique Carrión Ordóñez, Lima [sin paginación].

Santillán, Hernando de. 1968 (1563). Relacion del origen, descendencia, politica y gobierno de los Incas, Biblioteca Peruana, Primera Serie, Tomo III, Lima, Editores Asociados, ETA.

Sepúlveda, Jairo, San Francisco, Alex, Jiménez, Bruno y Pérez, Sebastián. 2014. El pucará del cerro La Muralla: Mapuches, Incas y españoles en el Valle del Cachapoal, Santiago, Mutante editores. Servicio Nacional de Geología y Minería, SERNAGEOMIN. 2014. Sistema de información de yacimientos minerales de Chile, ficha $N^{\circ} 3202$, Yabricoya, Santiago.

Silva, Osvaldo. 1983. ¿Detuvo la batalla del Maule la expansión inca hacia el sur de Chile?, en Cuadernos de Historia, $\mathrm{N}^{\circ}$ 3, Santiago, pp. 7-25.

Silva, Osvaldo. 1986. "Los promaucaes y la frontera meridional incaica en Chile", en Cuadernos de Historia, $N^{\circ} 6$, Santiago, pp. 7-16. 
Sotomayor, Gonzalo, Stehberg, Rubén y Cerda, Juan Carlos. 2016. "Mapocho incaico norte", Museo Nacional de Historia Natural, Chile, № 65, Santiago, pp. 109-135.

Stange, Fredy, Collao, Santiago y Helle, Sonia. 2012. "Posibles fuentes de los placeres auríferos en la Cordillera de la Costa, Región del Bio Bío”, en XIII Congreso Geológico Chileno, Antofagasta, pp. 58-59.

Stehberg, Rubén. 1976. "La Fortaleza de Chena y su Relación con la Ocupación Incaica de Chile Central", en Publicación Ocasional del Museo Nacional de Historia Natural de Chile, № 23, Santiago, pp. 3-37.

Stehberg, Rubén. 1991. "El límite inferior cronológico de la expansión incaica en Chile", en Xama, $\mathrm{N}^{\circ} 4,5$, Mendoza, pp. 63-89.

Stehberg, Rubén. 2013. "Caminos, guacas y el reducto fortificado de cerro el peral: instalaciones para el control inca del paso de Chada, Chile Central", en Boletín del Museo Nacional de Historia Natural, №62, Mendoza, pp. 129-146.

Stehberg, Rubén. 2016. "Plataforma ceremonial Ushnu inca de Chena, Valle del Maipo, Chile", en Chungara, Vol. 48, № 4, Arica, pp. 557-588.

Stehberg, Rubén, Planella, Maria Teresa y Niemeyer, Hans. 1997. "Complejidad arquitectónica de las ruinas prehispánicas de Chada en la antigua ruta entre los ríos Maipo y Cachapoal", en Xama, № 6, 11, Mendoza, pp. 53-64.

Stehberg, Rubén y Rodríguez, Antonio. 1989. "Ofertorio mapuche-incaico en el cerro Tren de Doñihue", en Revista Museos, № 6, Santiago, pp. 8-11.

Stehberg, Rubén y Rodríguez, Antonio. 1995. "Ofrendas mapuche-incaicas en el cerro Tren-Tren de Doñihue, valle de Cachapoal”, en Revista Tawantinsuyu N 1, Canberra, pp. 29-35.

Stehberg, Rubén y Sotomayor, Gonzalo. 2012. "El Mapocho Incaico", en Boletín del Museo Nacional de Historia Natural, N 61, Santiago, pp. 85-149.

Téllez, Eduardo. 1990. “De incas, picones y promaucaes", en Cuadernos de Historia, №10, Santiago, pp. 69-86.

Uhle, Max. 1911. La esfera de influencia del país de los Incas, IV Congreso cientifico $\left(1^{\circ}\right.$ panamericano). Ciencias Naturales, Antropológicas y Etnológicas del 25 de diciembre de 1908 al 5 de enero de 1909, Tomo II. Santiago, pp. 260-281.

Uhle, Max. 1912. "Arqueología Sudamericana”, en Revista Chilena de Historia y Geografía, N IV, 8, Santiago, pp. 411-425.

Uribe, Mauricio y Sánchez, Rodrigo. 2016. "Los incas en Chile. Aportes de la arqueología chilena a la historia del Tawantinsuyo (ca. 1400 a 1536 años d.C.)", en Falabella, Fernando, Uribe, Mauricio, Sanhueza, Lorena, Aldunate, Carlos e Hidalgo, Jorge (eds.). Prehistoria en Chile desde sus primeros habitantes hasta los Incas, Santiago, Editorial Universitaria, pp. 529-572.

Valdivia, Pedro de. 1929 (1545-1552). Cartas de Pedro de Valdivia que tratan del descubrimiento y conquista de Chile, Toribio Medina, José (ed.). Sevilla, Establecimientos tipográficos de M. Carmona.

Vega, Garcilaso de la 1609. Comentarios Reales, Lisboa, Oficina de Pedro Crasbeeck. 
Vivar, Jerónimo de. 1966 (1558). Crónica y relación copiosa y verdadera de los reynos de Chile hecha por Gerónimo de Bibar, Santiago, Fondo histórico y bibliográfico José Toribio Medina, Biblioteca Nacional de Chile.

Zavala, José Manuel y Dillehay, Tom. 2010. “El 'Estado de Arauco' frente a la conquista española: estructuración sociopolítica y ritual de los araucano-mapuches en los valles nahuelbutanos durante los siglos XVI y XVII", en Chungara, N42, 2, Arica, pp. 433-450.

Zavala, José Manuel, Bachraty, Dagmar y Payàs, Gertrudis. 2021. "El pron o quipu mapuche según fuentes coloniales y datos arqueológicos: antecedentes sobre su origen, uso y función", en Boletín del Museo Chileno de Arte Precolombino, Vol. 26, №1, Santiago, pp. 41-55. 